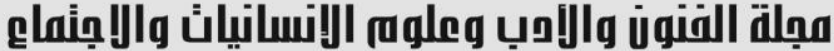

\section{أخوة محمد للروائية ميسلون هادي \\ (دراسة تحليلية)}

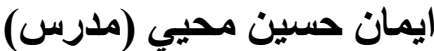

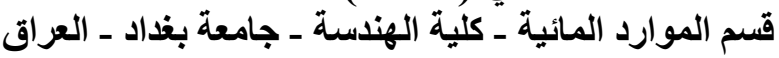

eman.h.m@coeng.uobaghdad.edu.iq :الايميل

الملخص

مع اثتعال نير ان الحرب في العراق لاسيما حقبة التسعينيات وفرض الحصار الاقتصادي الذي دام لسنوات عدة تليها حرب 2003 التي انتهت بسقوط النظام انذاك. من رحم تلك الازمة انبثقت أديبات لامعات في المجال القصصي والروائي، سجلن بصمة وضاءة في الأدب العر اقي ولاسيما روايات الحرب. ومع نزامن الاحداث

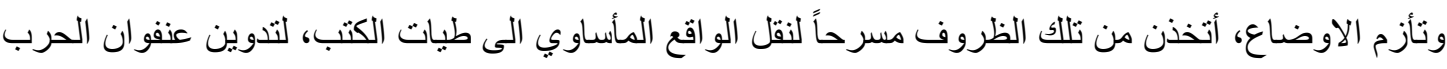
بصور و اشكال ومواقف عدة فقد ظهرت مواهب عديدة في ظل تلك الظروف، استطعن أن يطلقن العنان لقلمهن ليخط كلمات الو اقع الأليم محاو لات تصوير الأحداث المتلاطمة وبشاعتها، فتارت لديهن قوة التعبير وفن الكتابة ومن تللك الاديبات، ميسلون هادي.

وتتكون الرو اية بشكل عام من عناصر بنائية تتهض بفصول الرواية مثل الثخصيات و الامكنة والازمنة وغير ها

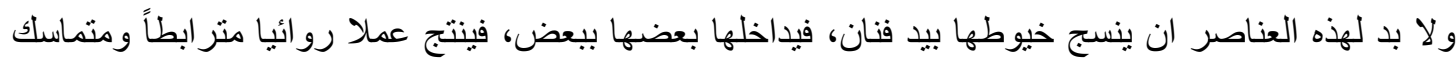
الاجز اء.

الكلمات المفتاحية: ميسلون هادي، رواية أخوة محمد، الحوار والوصف. 


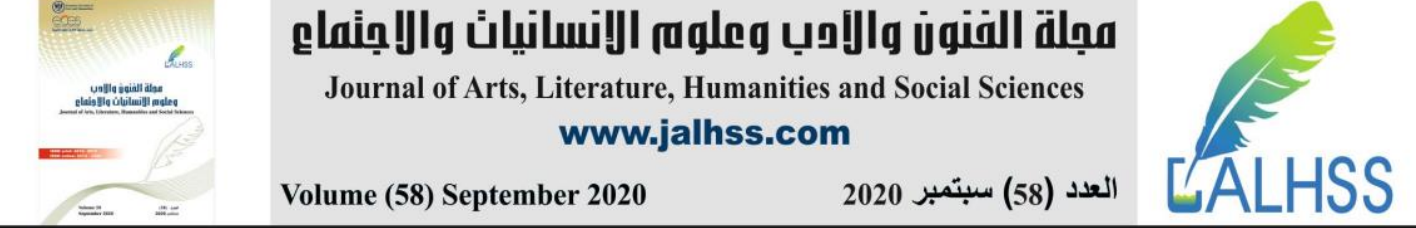 \\ Mohammed's Brothers of the Novelist Maysaloon Hadi (An analytical study)
}

\section{Lect. Eman Hussein Muhyee}

University of Baghdad - College of Engineering -Iraq

Email: eman.h.m@coeng.uobaghdad.edu.iq

\begin{abstract}
With the war fire ignition in Iraq, especially in the nineties, and the economic sanctions which continued for many years, followed by the 2003 war which ended by the fall of the regime, brilliant writers appeared in the novel and story fields. They had a clear mark in the Iraqi literature and specially in war novels. As the situation worsened, they transferred the tragic situation in these circumstances to their writings, to record the fury of war in different shapes and events. Several talents appeared in those circumstances, that were able to unleash their pen to draw the words of the painful reality and the efforts to represent the events and their monstrosity. So, their strength of expression and writing art revolted. One of these writers was Maysaloon Hadi.

In general, each novel consists of structural elements that rise the novel chapters, like the characters, places, times, and others. An artist must be the one that weaves strands of these elements and combines them to produce a novel with linked components.
\end{abstract}

Keywords: Maysaloun Hadi, a novel of brothers of Muhammad, dialogue and description. 


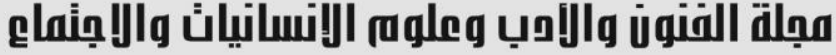

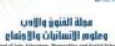

Journal of Arts, Literature, Humanities and Social Sciences www.jalhss.com

يقوم البحث على دراسة رواية (أخوة محمد) للروائية ميسلون هادي، وهي من الروايات العراتية العية في الادب

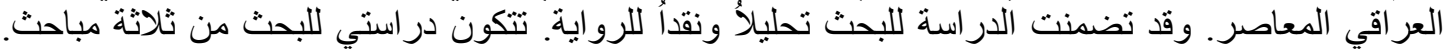

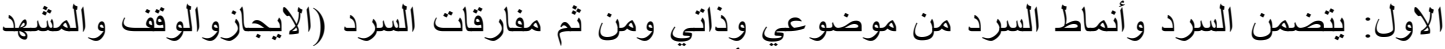

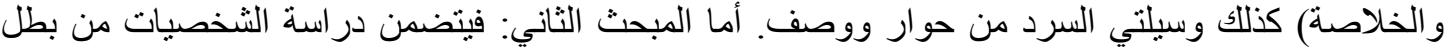

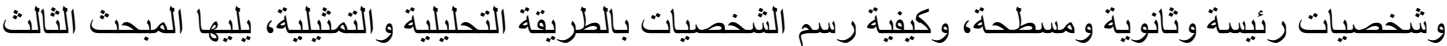
و الاخير و الذي يشمل المكان بنو عيه المعادي و الاليف، و الذي تدور فيه الاحداث. ثم نختم البحث بأهم النتائج التي توصلنا لها في در استنا للموضوان عنوع.

\section{المبحث الاول}

طبيعة السرد و أنماطه: قبل الدخول و الولوج الى طبيعة السرد يجدر بنا ان نعرف ما السرد في اللغة و الاصطلاح.

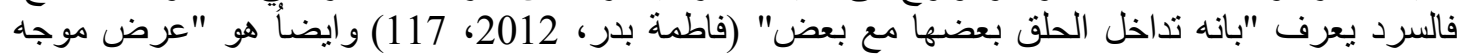

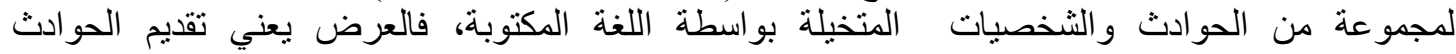

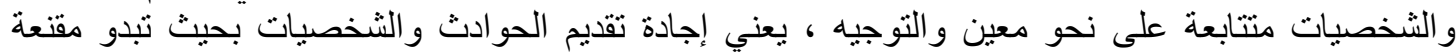
لللمروي له"( حسن رشاد الثامي، 1998، 279).

أما السرد في الاصطلاح: "فهو العملية التي يقوم بها السارد أو الراوي (الحاكي) لينتج عنها النص القصصي

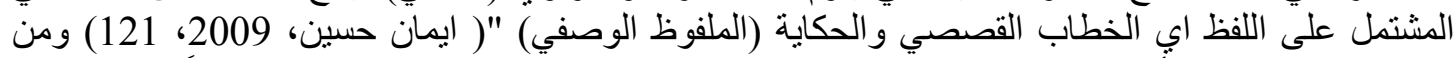

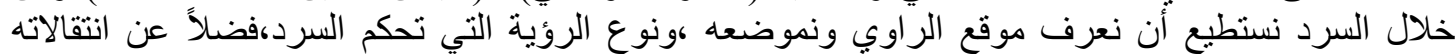

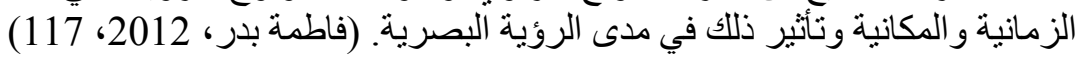

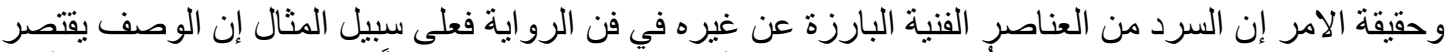

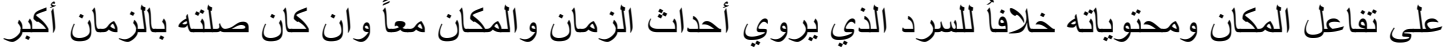

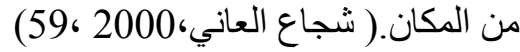

\section{طبيعة السرد}

يذكر الناقد بأن الثكلاني الروسي (تومانشفكي) قد ميز بين نوعين من السرد 1. موضوعي 2. الذاتي

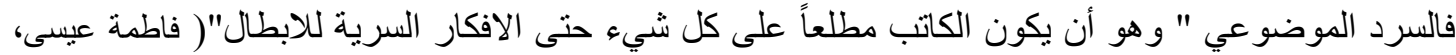

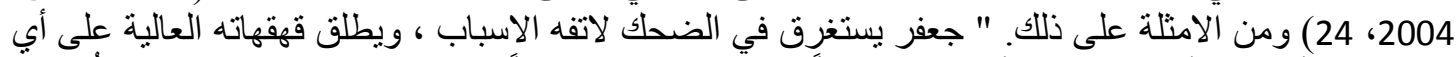

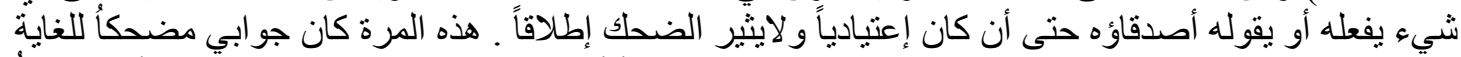

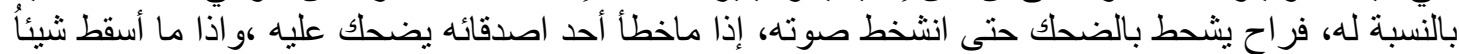

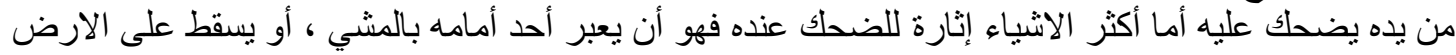

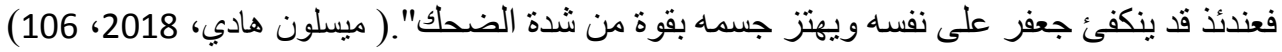

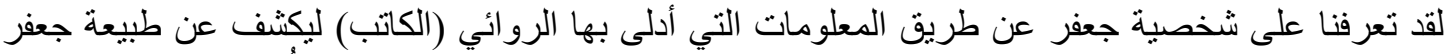

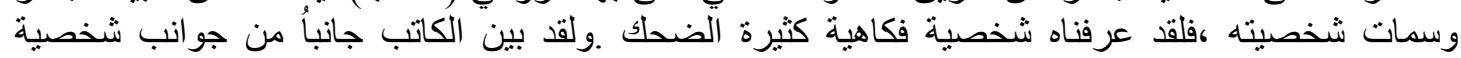
(جعفر) و هذا الجانب يتعلق بحياته الخاصة.

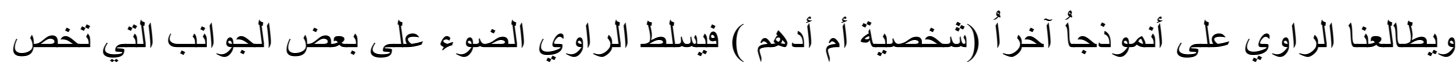

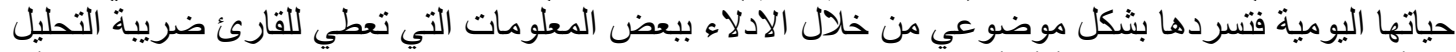

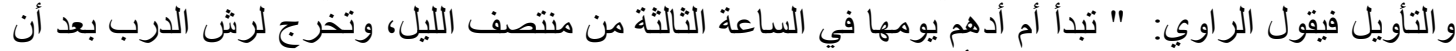

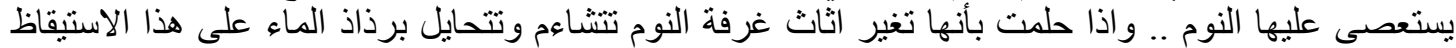

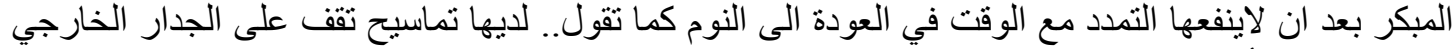

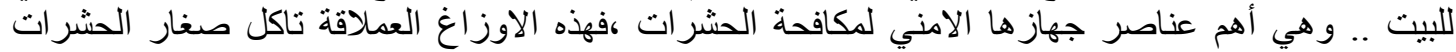




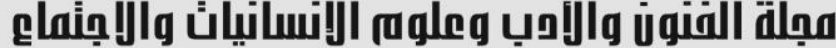

Journal of Arts, Literature, Humanities and Social Sciences www.jalhss.com

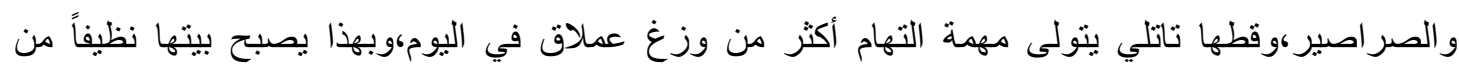

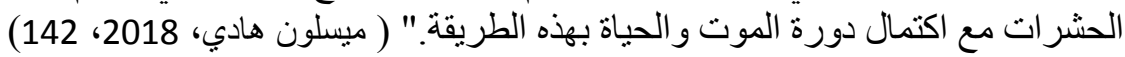

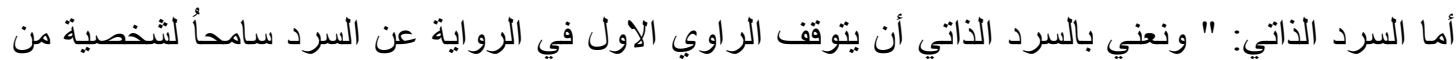

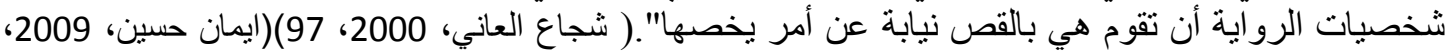

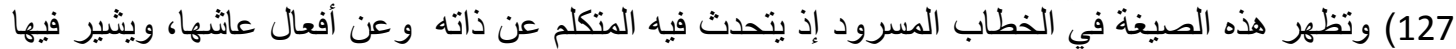
الى أثشياء تمت في الماضي .( أحمد عبد الرزاق، 2015، 50)

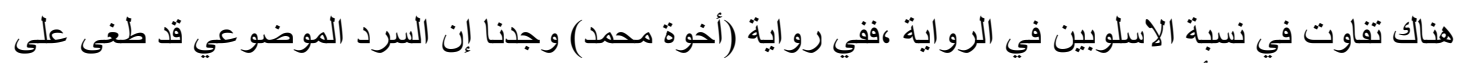

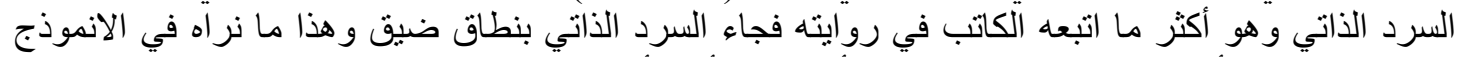

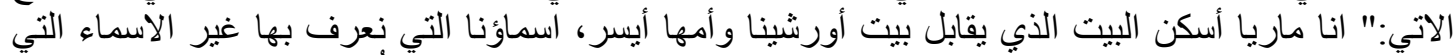

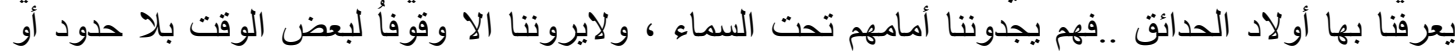

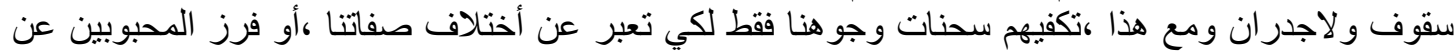

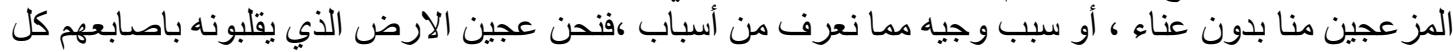

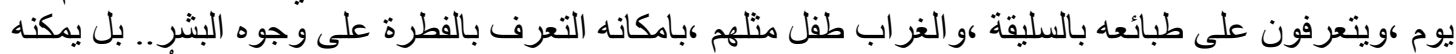

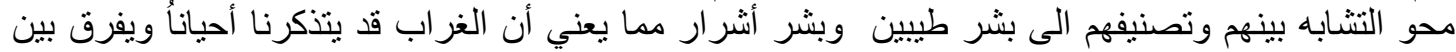
وجوه الصور ووجو هنا"( ميسلون هادي، 2018، 50).

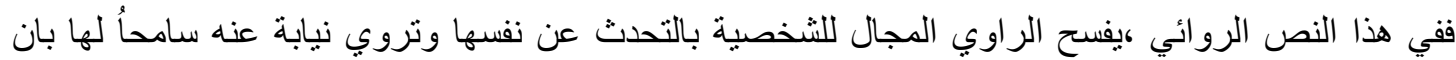

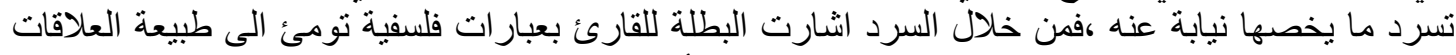

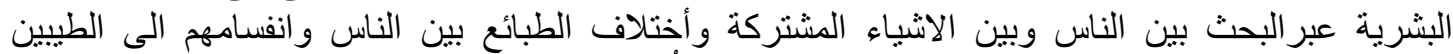

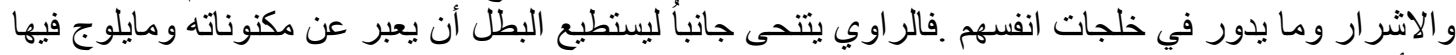

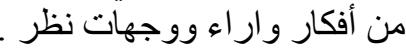

\section{مفارقات السرد}

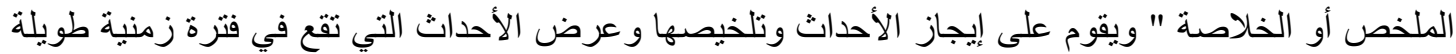

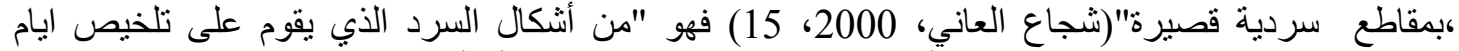

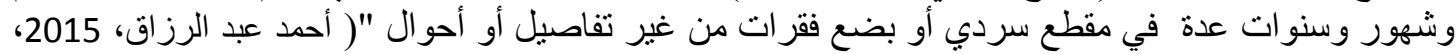

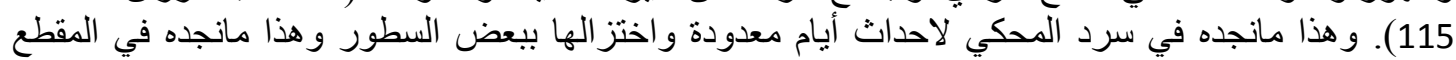
السردي.

" منذ اليوم الاول وحتى اليوم الأخير للامتحانات ،لم يتصل بي، يصعد كل يوم الى السطح المظلم للئل اللغاية من سلم

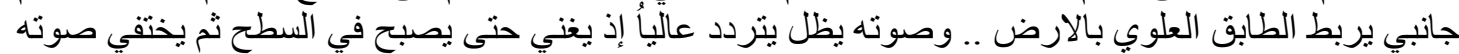

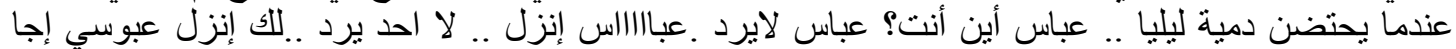

أبوك .. فينزل ليساعده في ملء خزان النفط من المحط منتصف الليل." (ميسلون هادي، 2018، 73)

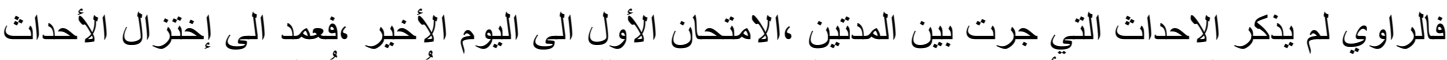

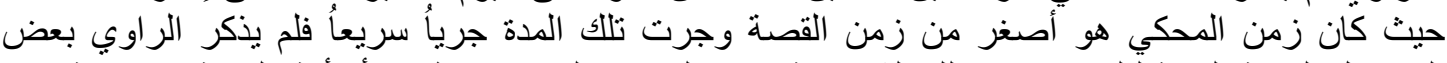

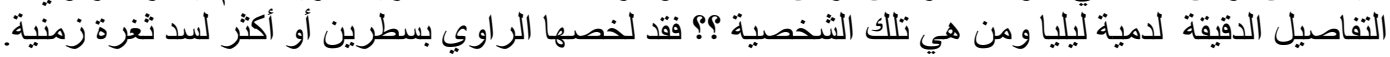

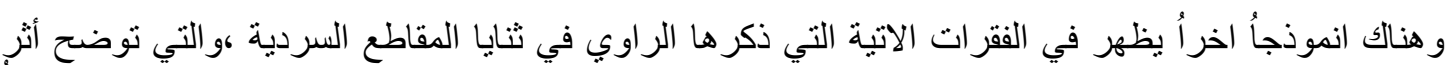

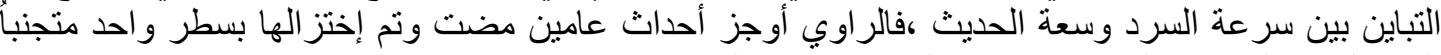
التفصيل في الحو ادث الماضية فنر اه يقول في عبار اته الحوارية:

$$
\text { " هل توجد نافذة في البيت ؟ }
$$

البيت مغلق منذ عامين ، ونحن نسكن في المشتمل و الحديقة ولاندخل إليه "( ميسلون هادي، 2018، 137) 


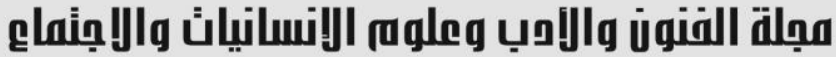

Journal of Arts, Literature, Humanities and Social Sciences www.jalhss.com

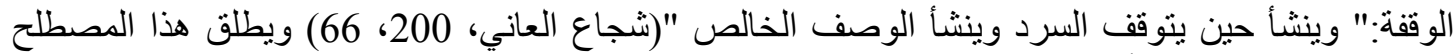

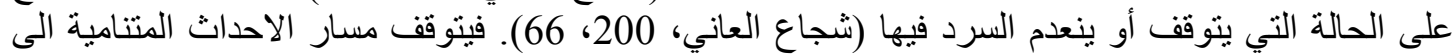

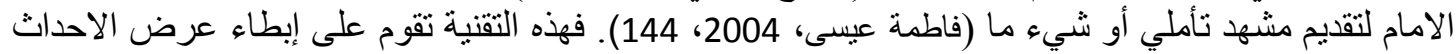

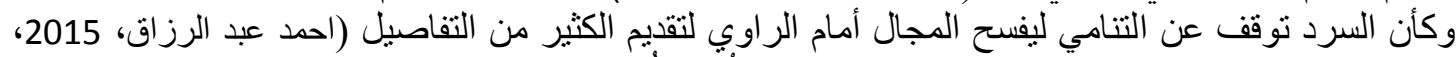

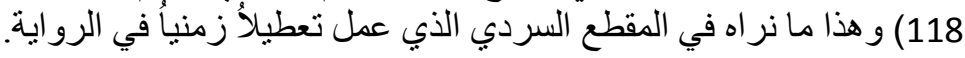

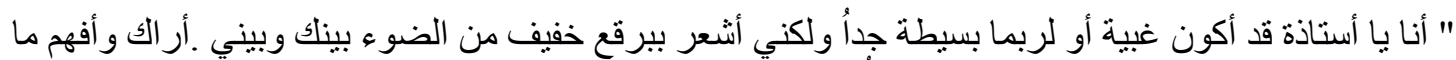

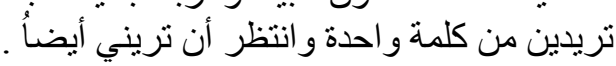

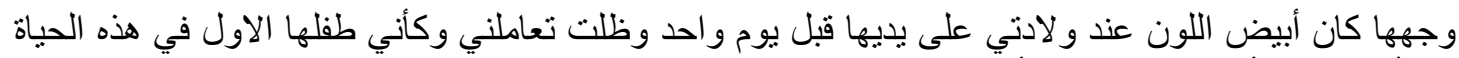

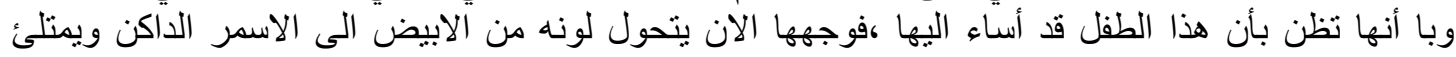

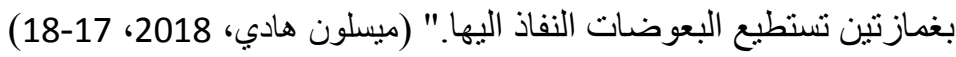

فقد لجأ الراوي الى التوقف على بعض المقاطع الوصفية لابطاء الزمن أو توقفه مما أدى الى توقف زمن القصة

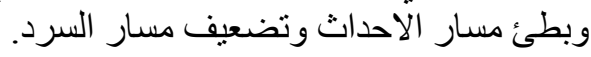

الحذف : ويقوم على أساس حذف الاحداث التي تقع في فترة معينة و الاشارة الى تللك الفترة" (شجاع العاني،

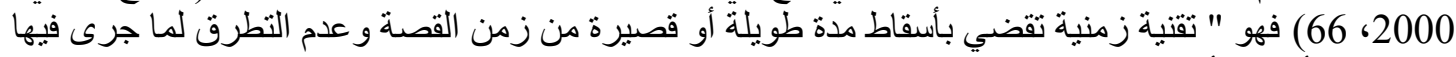
من وقائع و أحداث أو إنه المقطع المسقط في النص من زمن القصة " (احمد عبد الرزاق، 2015، 1116)

$$
\text { ويقسم الى قسمين 1- حذف صريح 2- حذف ضمني }
$$

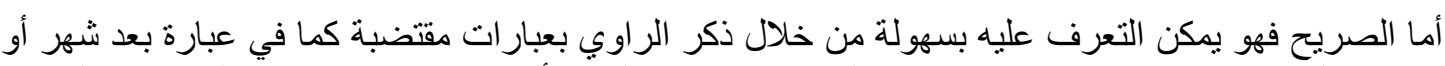

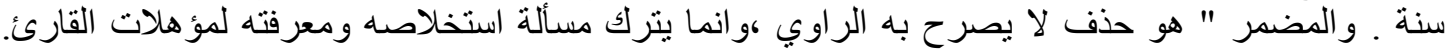

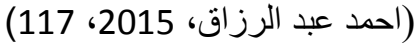

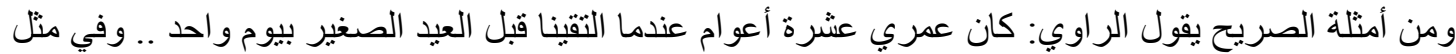

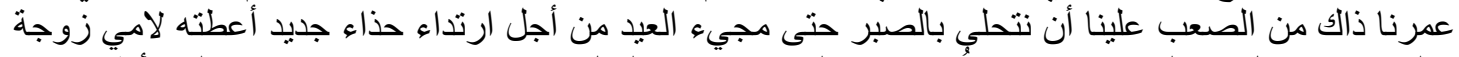

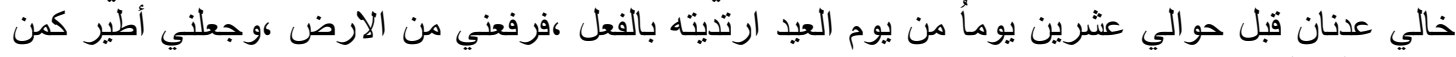

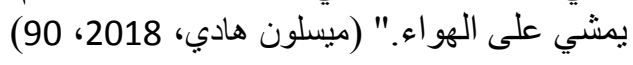

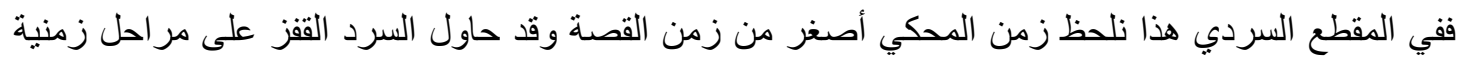

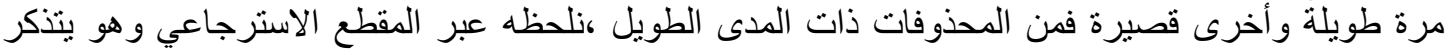

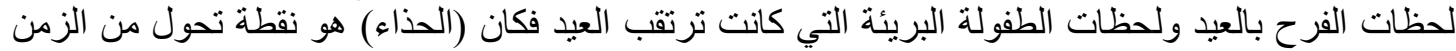

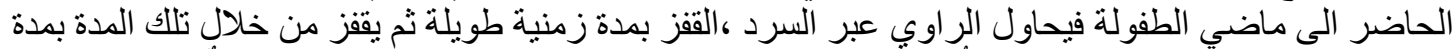

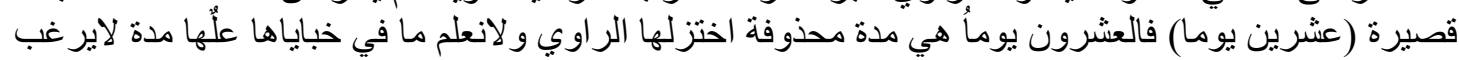

الر اوي كثفها.

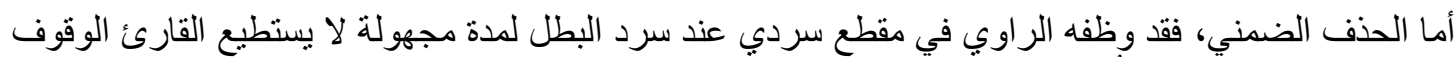

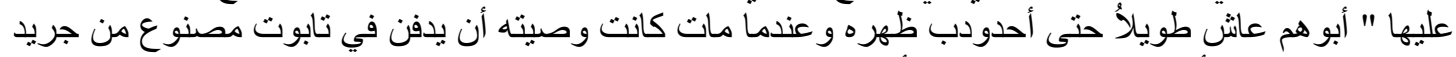

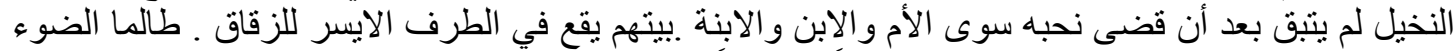

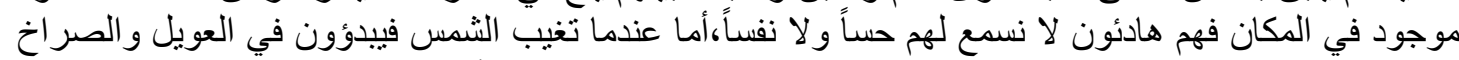

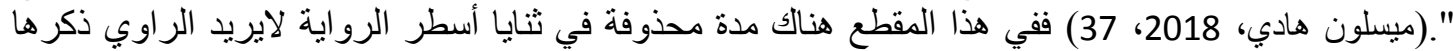
،لكنها كانت إيماءة للقارئ لحالة العوز و الفقر التي تعيشها تلكئ الاسرة لا سيما بعد موت الأب الذي الذي أكهله العوز و الفقر.

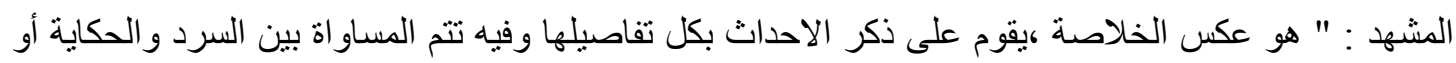

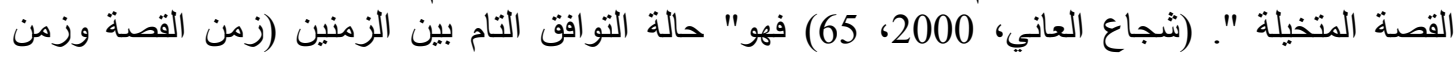




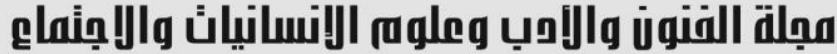

Journal of Arts, Literature, Humanities and Social Sciences www.jalhss.com

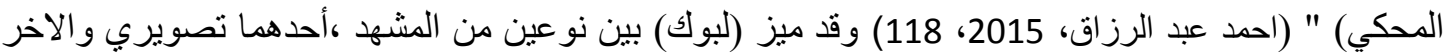

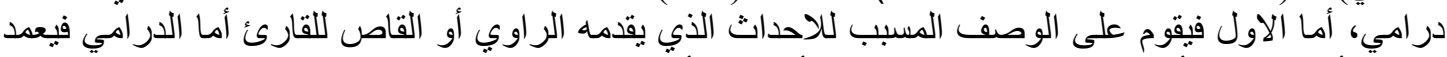

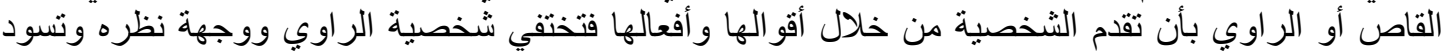

وجهة نظر القارئ. (شجاع العاني، 2000، 67 النقان

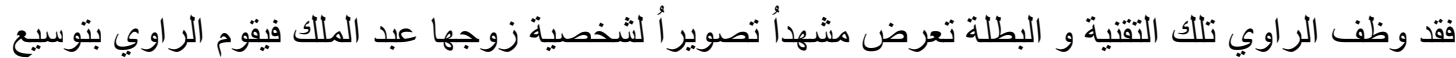

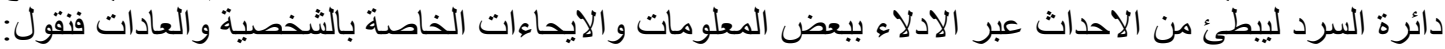

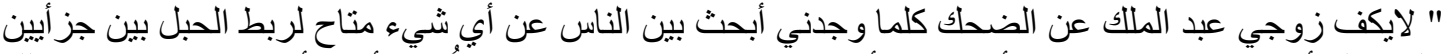

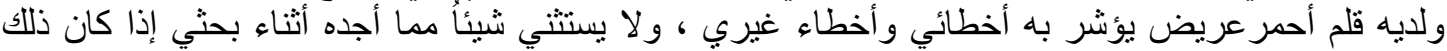

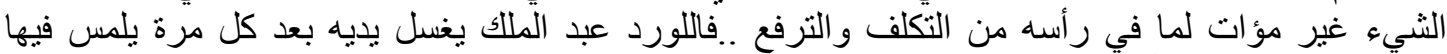
النقود،و لايمد يده أصلاً للمصافحة أية يد سقيمة عقيمة لثخص غريب ويعيش في الاماكن الفقيرة". (ميسلون

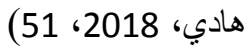

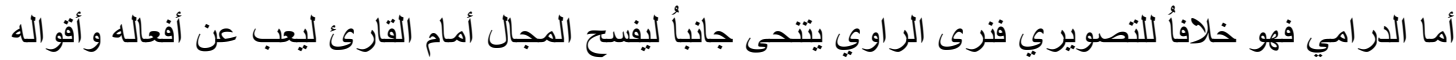

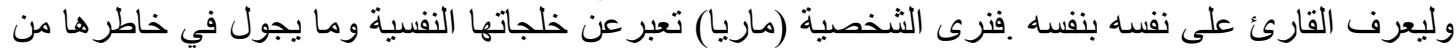

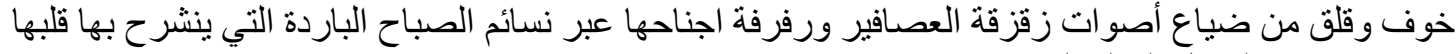

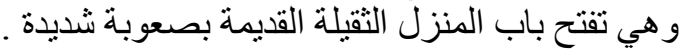

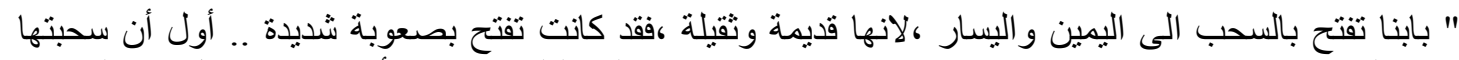

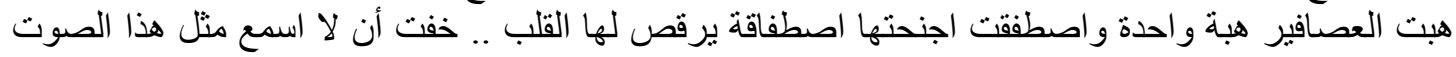

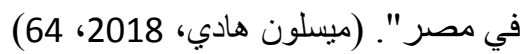

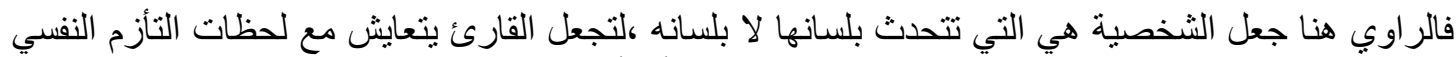

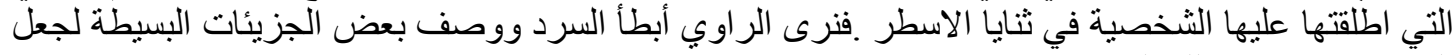
القارئ يتعايش مع نلك الثخصية.

\section{وسيلتّا السرد \\ الحوار - الوصف}

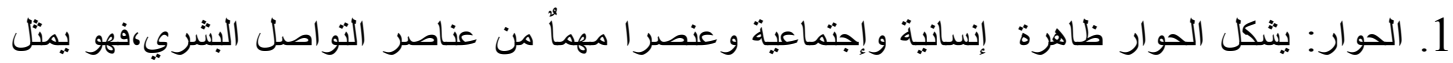

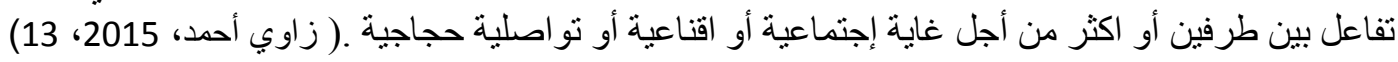

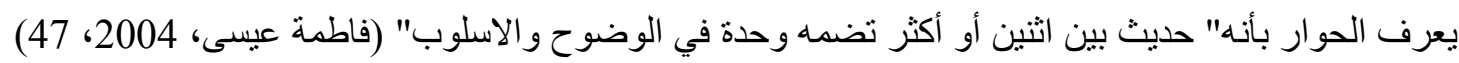
فهو نمط تو اصلي ،يتبادل ويتعاقب الاشخاص على الارسال و التلقي. (احمد عبد الرزاق، 2015، 182) وللحوار وظائف عدة منها:

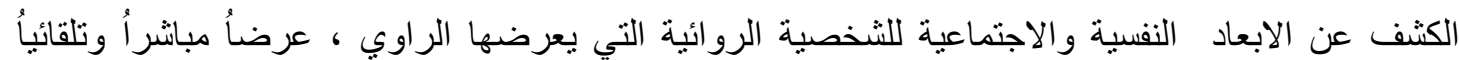

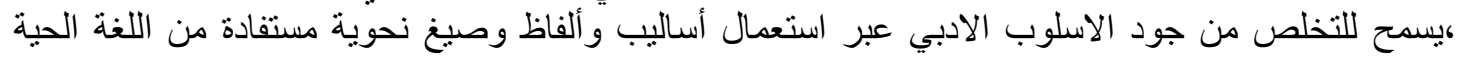

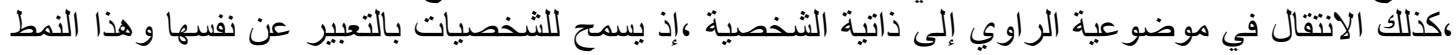

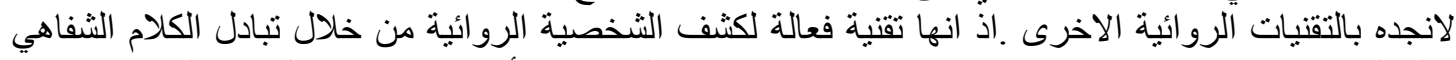

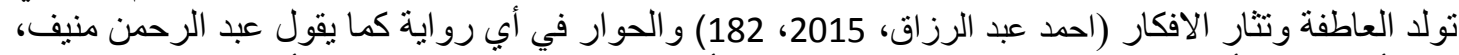

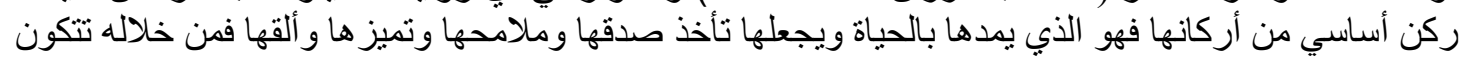

سمات الثخصية لان الثخصية تحدد من خلال فعلها ورد فعلها. (بشرى ياسين محمد، 2011، 62)

أما فيما يخص الحوار في رواية (أخوة محمد) فقد تشكل لاى (ميسلون هادي) المحرك الاساسي لافع الاحداث

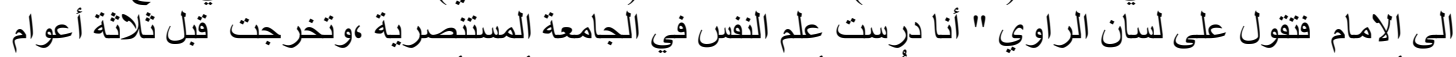

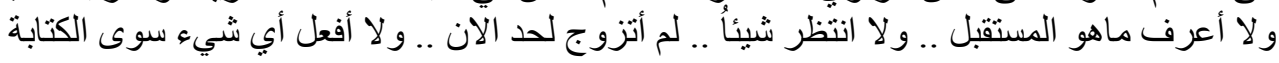




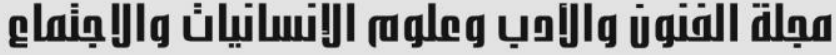

Journal of Arts, Literature, Humanities and Social Sciences www.jalhss.com

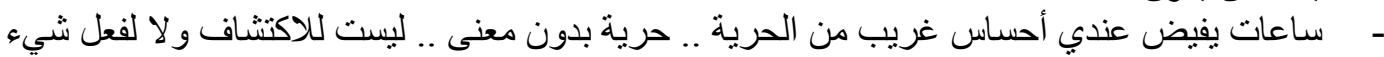

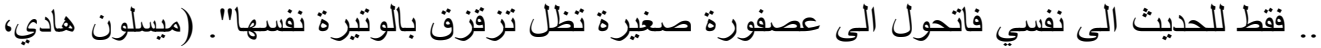

(39، 2018

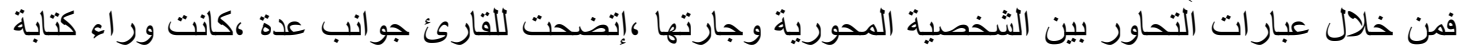

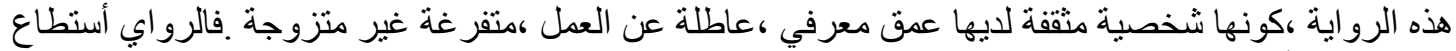

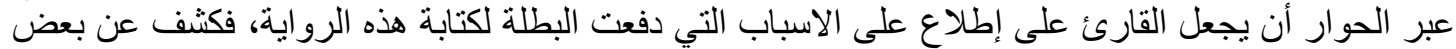

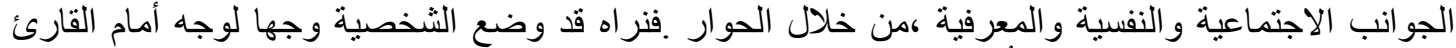

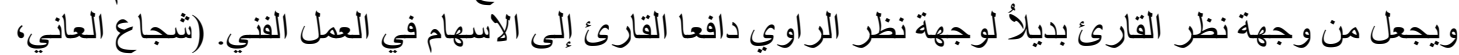

2 ـ الوصف يعرف الوصف بأنه " عرض وتقديم الاشياء و الكائنات و الوقائع و الحوادث (المجردة) من (الغاية

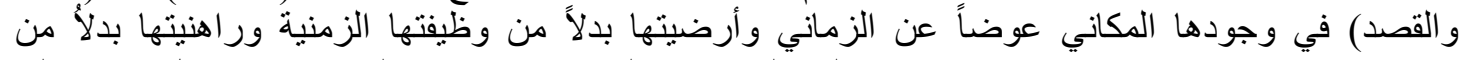

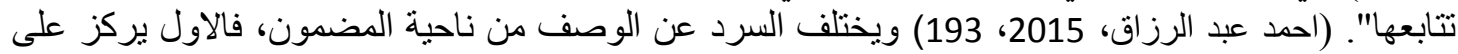

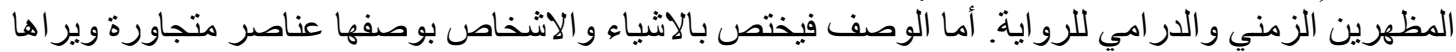

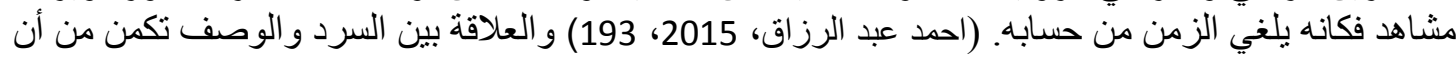

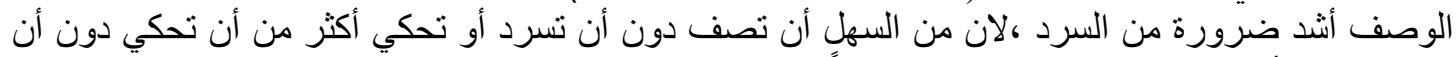

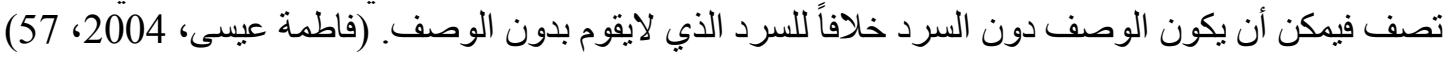
وقد حددت الدراسات الوصف بمحددات وظيفية تبعاُ للمدارس الادبية منها (فاطمة بدر، 2012، 24-25): 1. الوظيفية التزبينية التزويقية وهو دور جمالي خالص يرمي الى إعداد لوحات فنبة نوضح جماليات الموصوف وتثكل إستراحة في مضمار السرد.

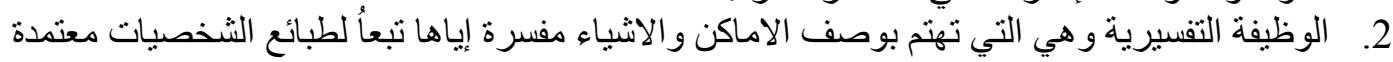

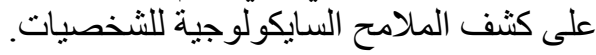

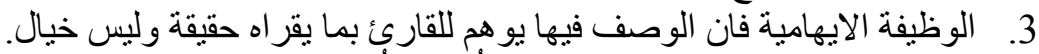
4. الوظيفة الرمزية ويكون الوصف دقيقاُ معتمداً على غلبة الحدس والرؤية الرية الباطنية ، إذ تتجه تفسيرات القارئ للاشياء ،تفسير ات رمزية بعيدة عن المألوف.

$$
\begin{aligned}
& \text { أما الوصف من حيث علاقته بالموصوف فيقسم الى : } \\
& \text { الوصف الاجمالي، الوصف التفصيلي }
\end{aligned}
$$

1. الوصف الاجمالي "وفيه تذكر بعض أجزاء الموصوف من دون مر اعاة التفاصيل الدقيقة". (احمد عبد

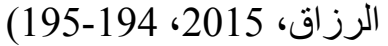

2. الوصف التفصيلي "وفيه يذكر كل أو معظم اجز اء الموصوف ومع هذا النوع تطول المقاطع الوصفية وتتفرع فتنكر الأمكنة وتفاصيل وصف الثخصيات. (احمد عبد الرزاق، 2015، 194-195)

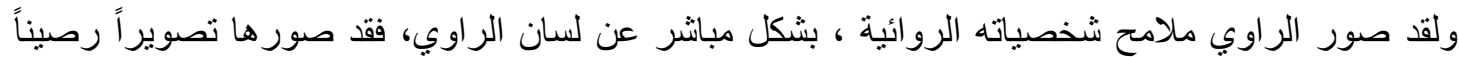

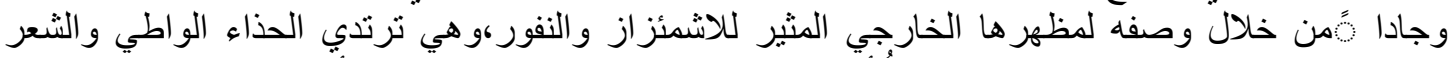

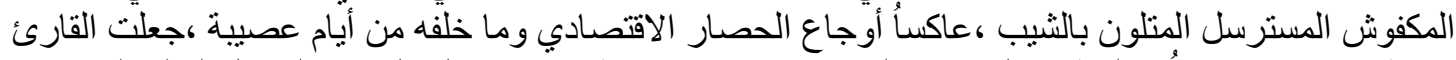

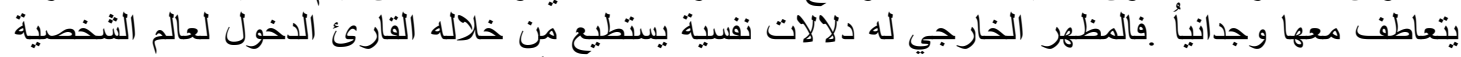

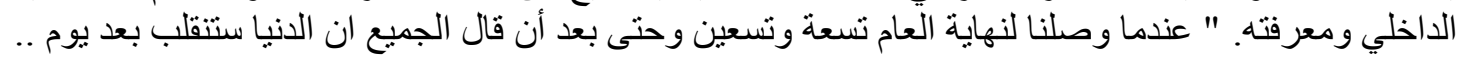




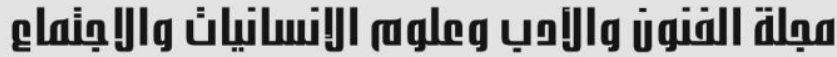

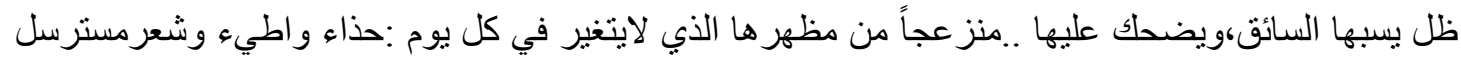

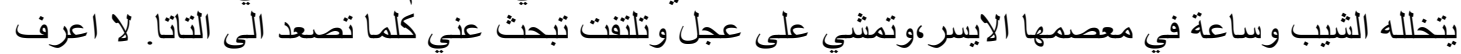

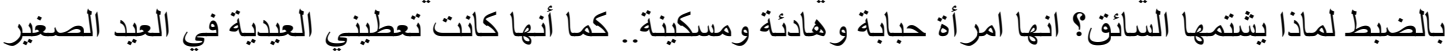

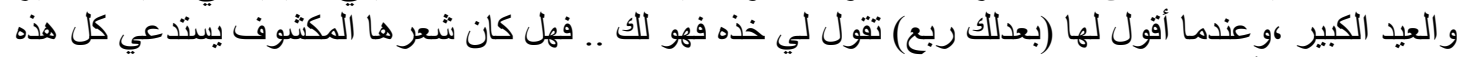

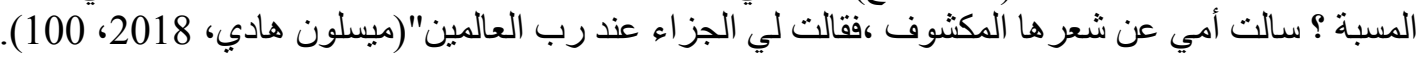

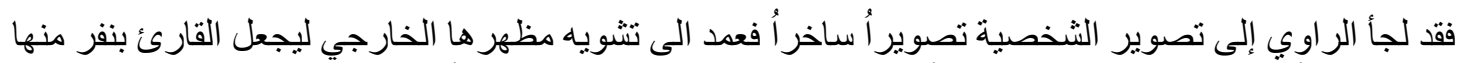

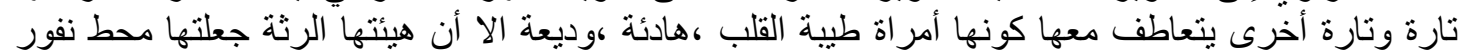

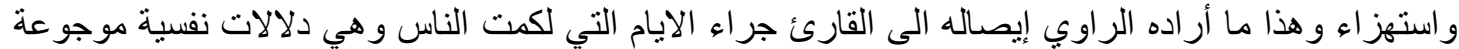

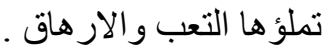

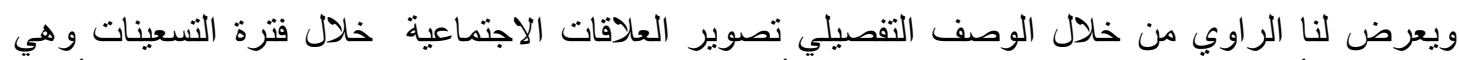

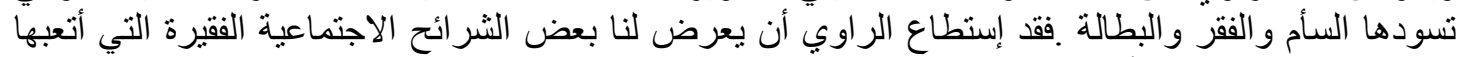

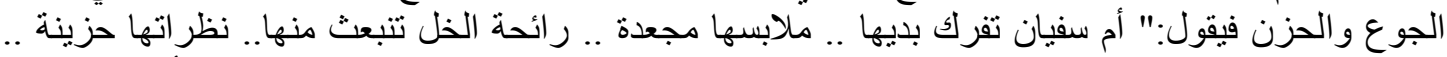

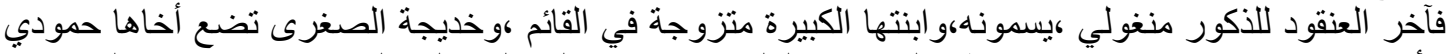

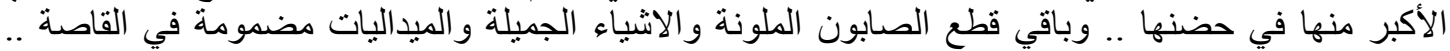

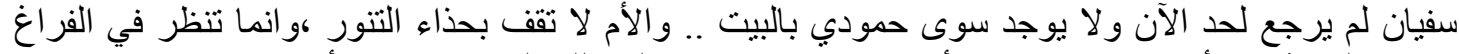

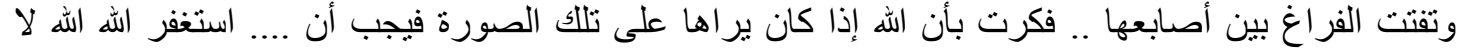

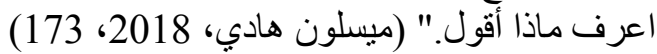

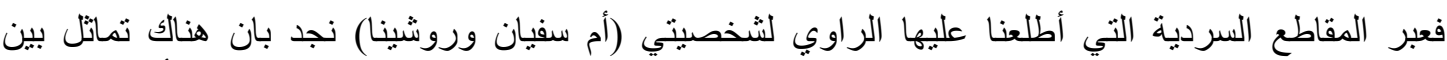

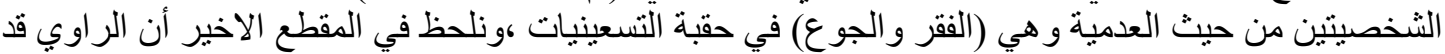

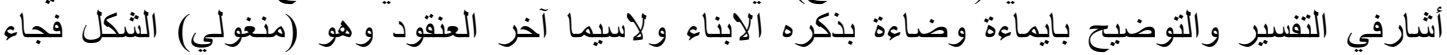

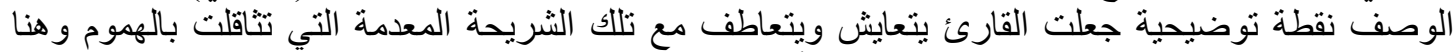

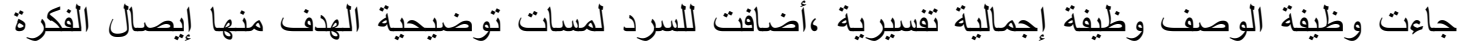

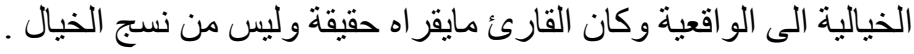

\section{المبحث الثاني

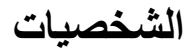

الثخصية في الرواية ،عنصر اُ مهمأ من عناصر الفن القصصي بوصفها النظام العصبي للقصة،قوقة إستحال

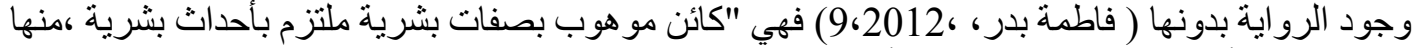

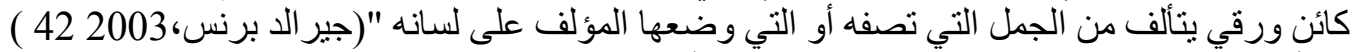

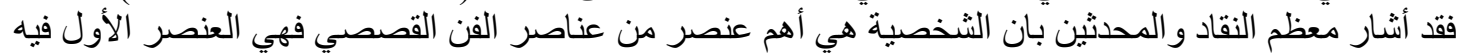

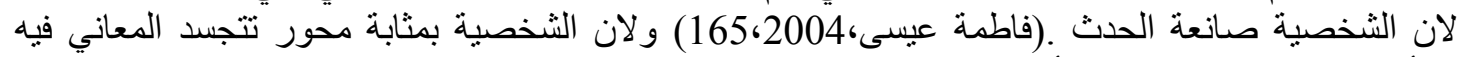

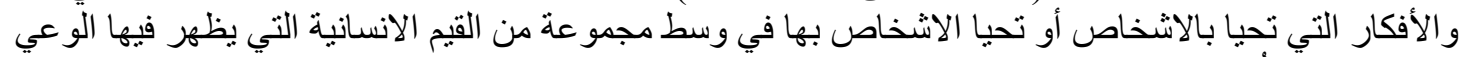

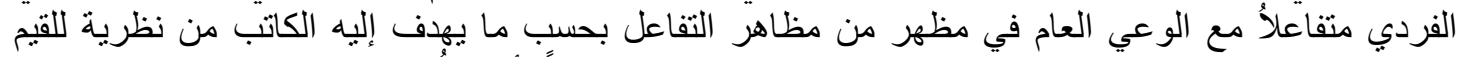
و المعايير الانسانية لهذا تعد الثخصية في الرواية الحديثة ركناً أساسياً في البناء الفني لها. (فاطمة عيسى، (80، ويمكن تصنيف الشخصيات من حيث أهميتها في الرواية و الوظيفة التي تقوم بها إلى :

$$
\text { 2. }
$$




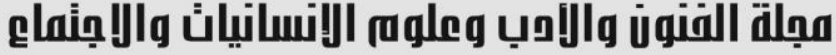

ويميز الناقد الانكليزي فورستر الثخصية الرئيسة بحسب عمقها أو سطحيتها أي شخصية مدورة أو مسطحة

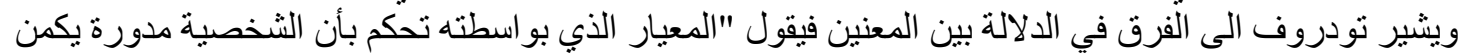

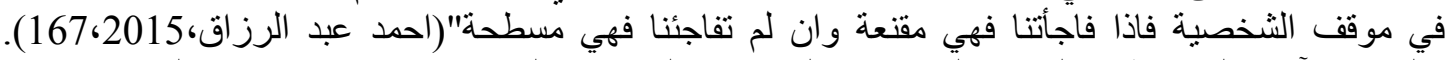

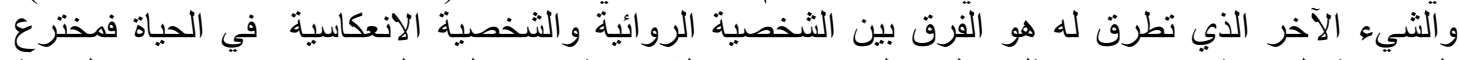

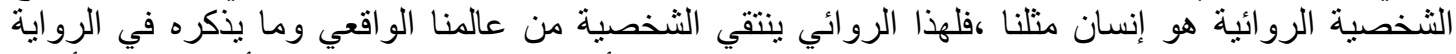

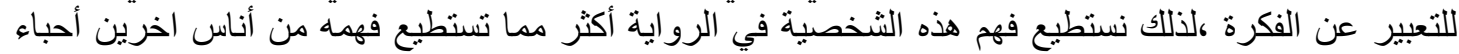

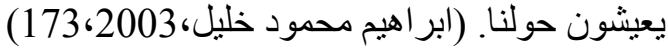

1. الثخصية (الرئيسة) وهي شخصية تتمحور حولها الأحداث والسرد فهي الفكرة الرئيسة التي تنسج

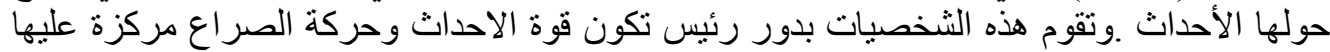

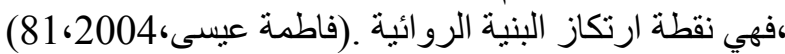

لقد إمتازت شخصيات رواية (أخوة محمد) بتعدد الثخصيات والتي تؤدي أدواراً مهمة فيها ومتميزة

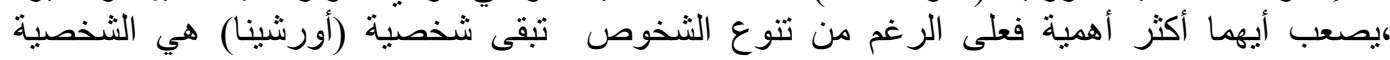

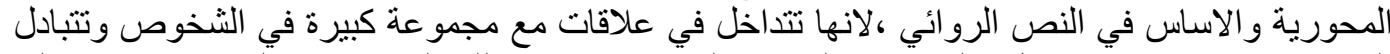

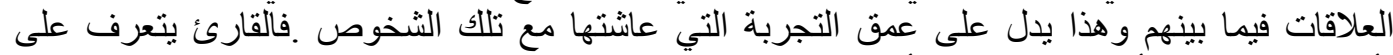

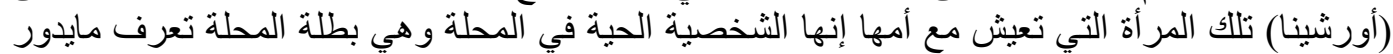

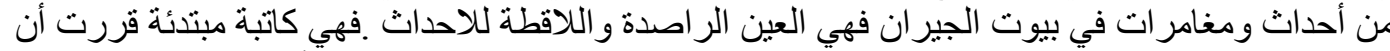

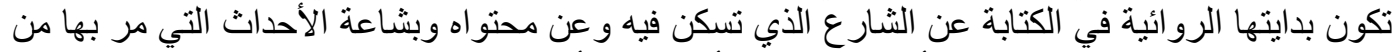

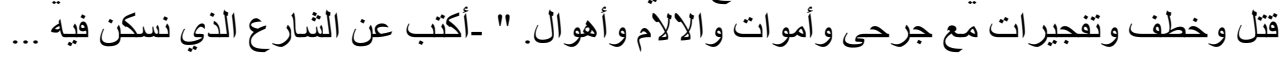

$$
\text { سأعد الثناذة. استاذة استاذة .. لماذا سكت؟ }
$$

لا .. لا أريد الشاي أستاذة أستاذة أستاذة .. أريد فقط أن تتصحيني .. قد أكون كتبت رواية غبية ،فأحبيتها

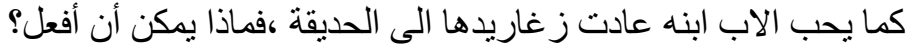

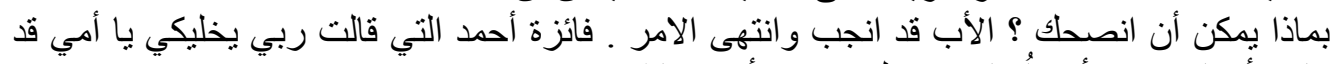

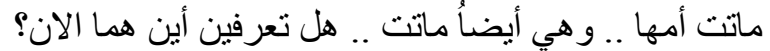

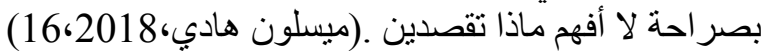

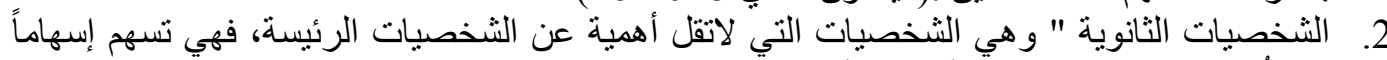

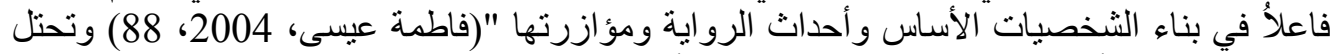

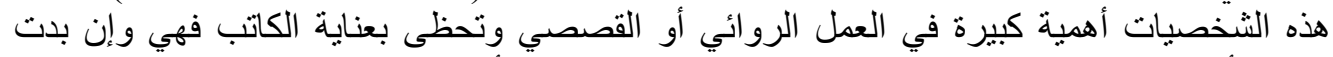

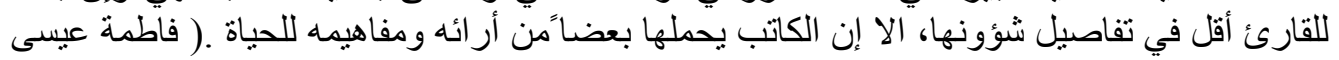

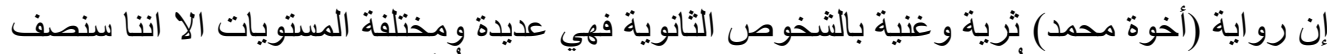

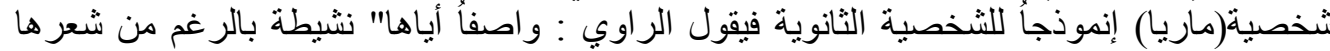

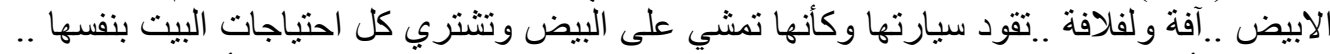

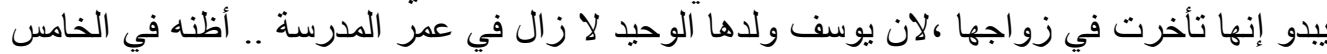

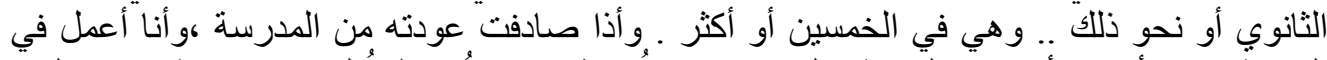

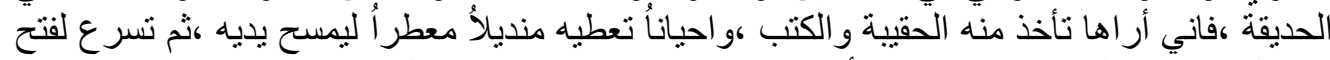

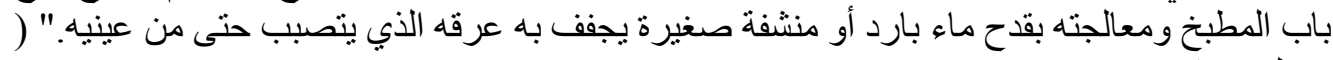

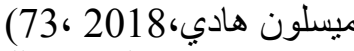

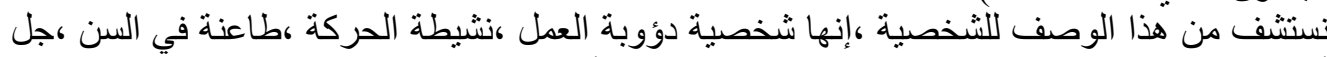

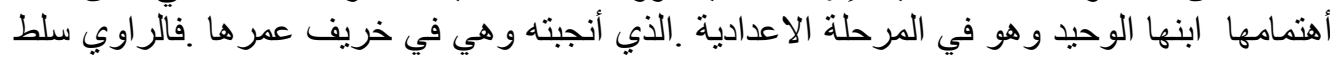

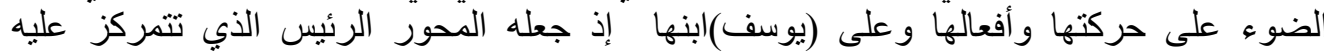

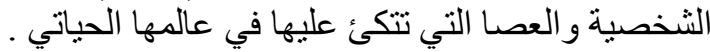




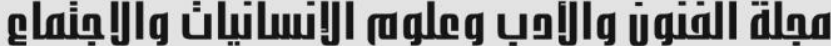

Journal of Arts, Literature, Humanities and Social Sciences www.jalhss.com

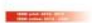

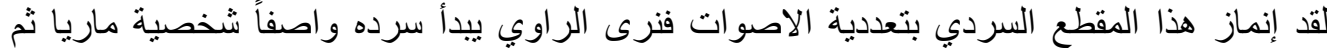

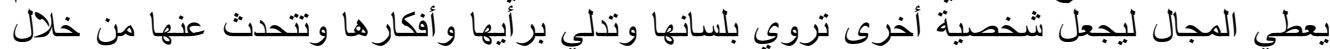

$$
\text { و الشخصيات تأني في العمل الأدبي بصورنين : }
$$

الثخصية الثابتة وهي الثخصية التي لاتتغير و لا تتطور بل تبقى ثابتة من بدايتها الى نهايتها .أما النامية فهي التي تتغير وتنطور وتتضج عبر تطور أحداث الرواية .

$$
\text { و هنالك نوعان من الشخصيات في العمل الروائي }
$$

1. الثخصبة المسطحة (الثابتة) 2. الثخصية المدورة(النامية)

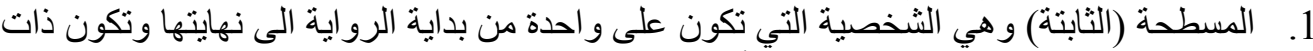

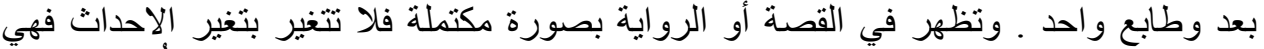

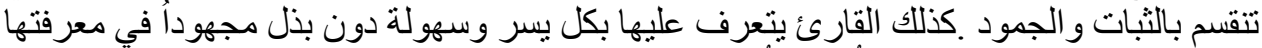

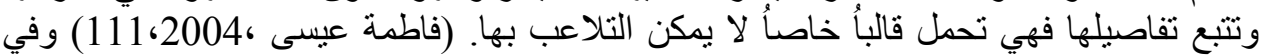

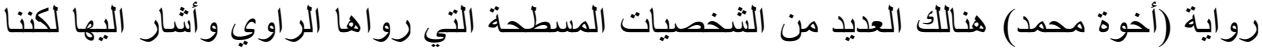

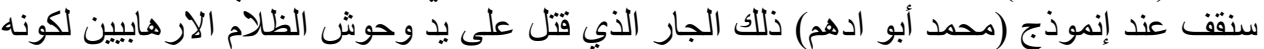

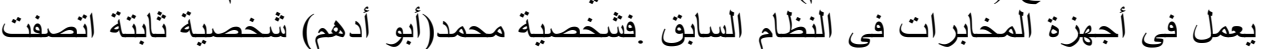

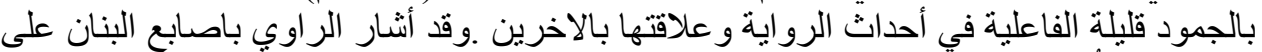

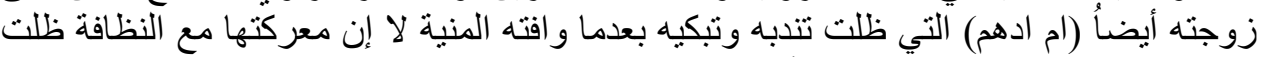

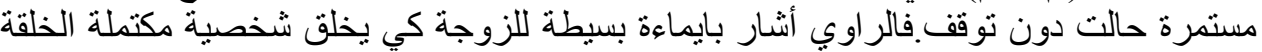

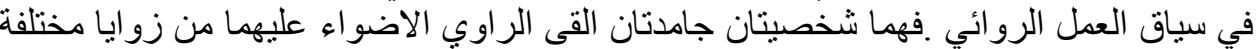

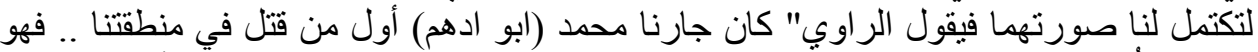

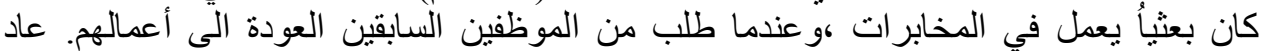

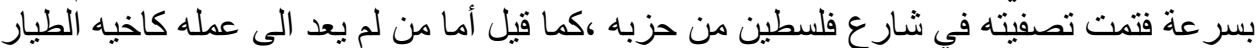

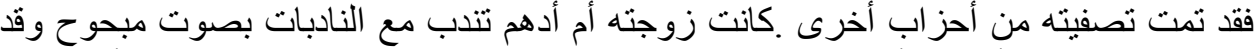

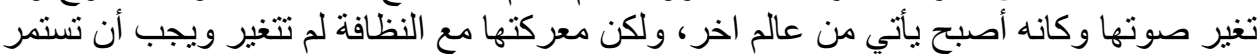

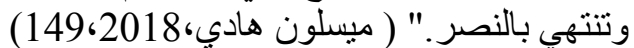

الثخصية النامية (المدورة) و هي التي تتطور وتتمو عبر نطور الرواية نفسها .وقد أثنار لها الناقد

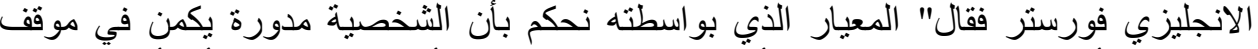
الشخصية فأن فاجاءتتا فهي مدورة وأن لم تفاجئنا فهي مقنعة أينا بانها مدورة المئه أما أن لم تفاجئنا

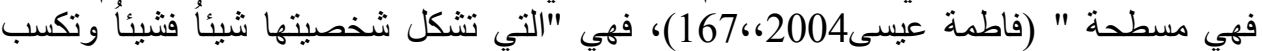

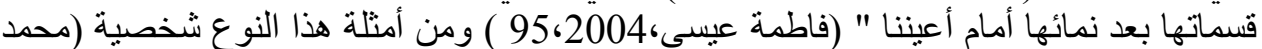

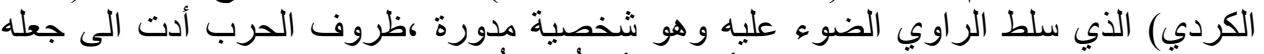

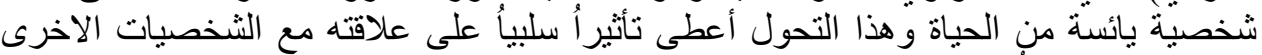

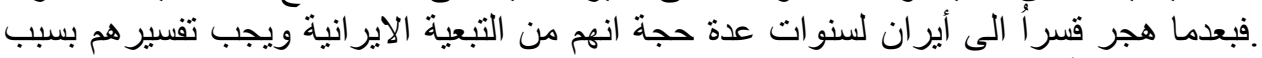

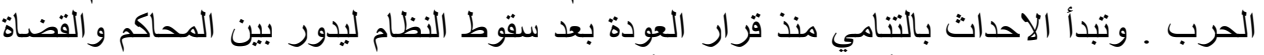

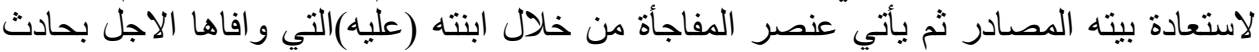

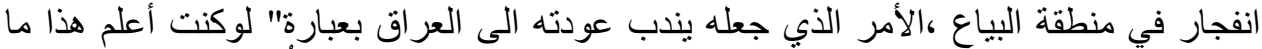

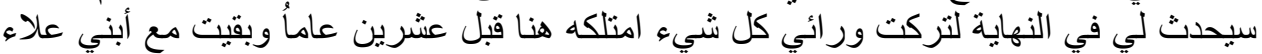

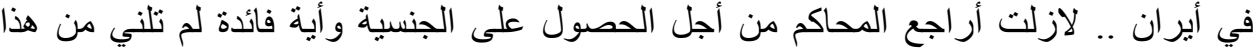




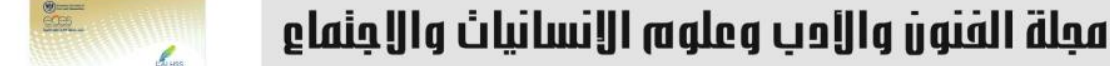 \\ Journal of Arts, Literature, Humanities and Social Sciences www.jalhss.com

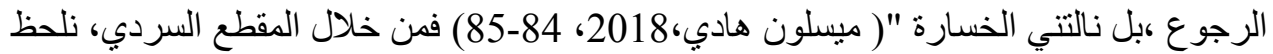
مدى إرتباط الحالة النفسية للثخصية بظروف الحرب هابل ونفوره منها.

ومن الجدير بالذكر بعد دراستتا لانماط الثخصيات ان ندرس التصنيفات الثنكلية للرواية المرتبطة بتقديم الثخصيات داخل السرد. وقد يلجأ الر اوي في تقديم شخصياته بطرق عدة الندان وقد ميز الناقد محمد يوسف النجم منها: 1 الطريقة التحليلية 2- الطريقة التمثيلية

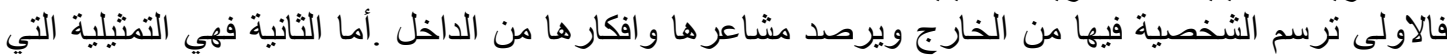

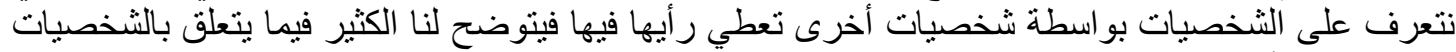

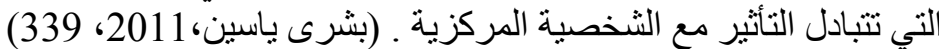

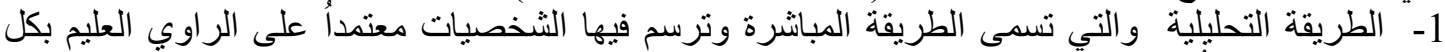

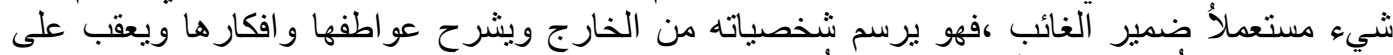

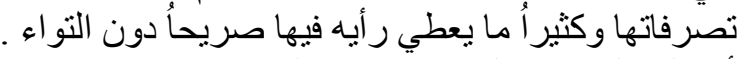
2- أما التمثيلية غير المباشرة ،فهي التي تعبر عن نفسها بنفسها مستعملة ضمير المتكلم فتكثف ابعادها للقارئ

وسماتها الخلقية بدون تكلف ،فتصفح عن مشاعر ها و أحاسيها الداخلية . (د.حسان رشاد ،205،1999)

الطريقة التحليلية

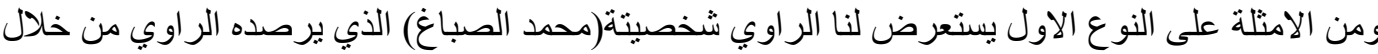

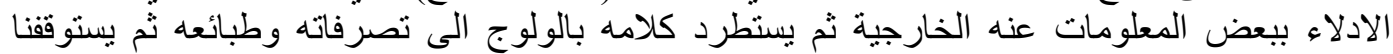

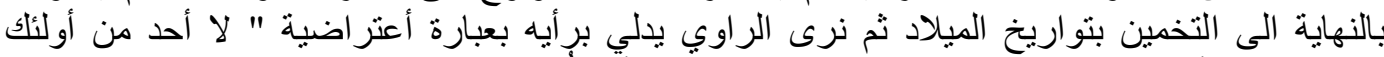

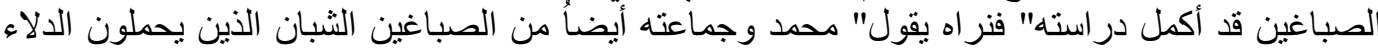

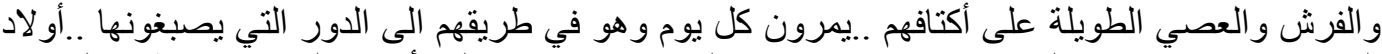

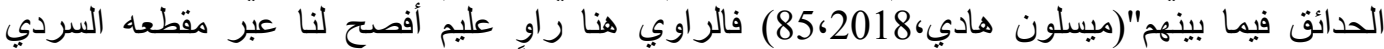

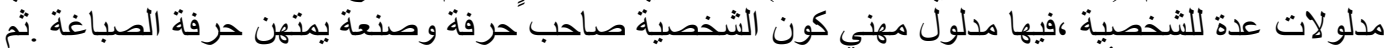

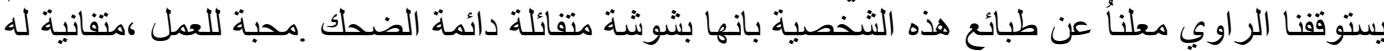

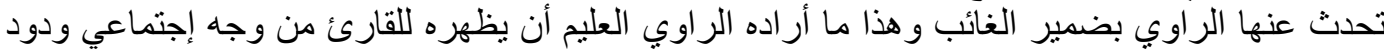

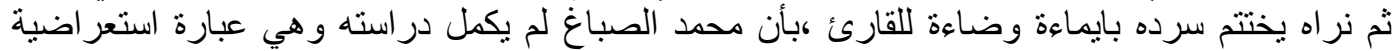

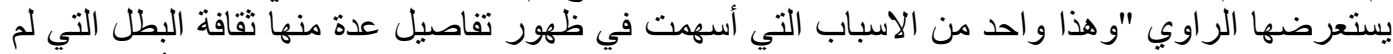

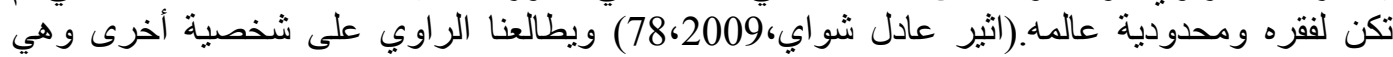

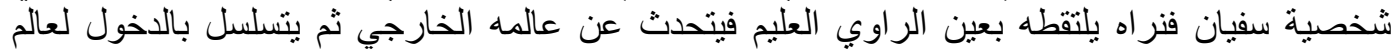

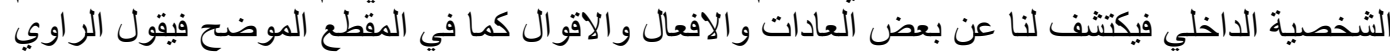

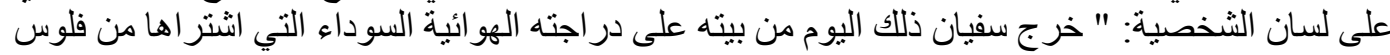

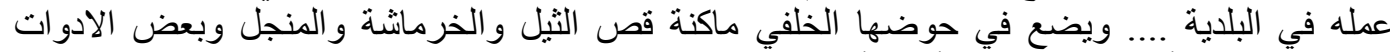

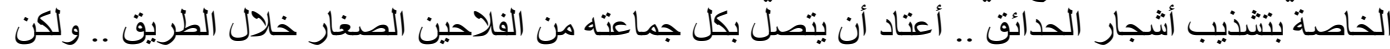

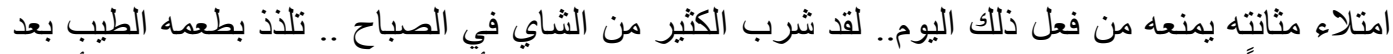

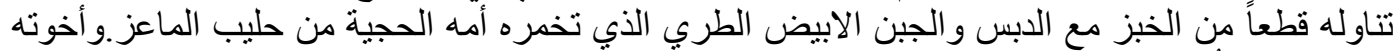

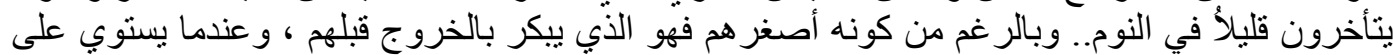

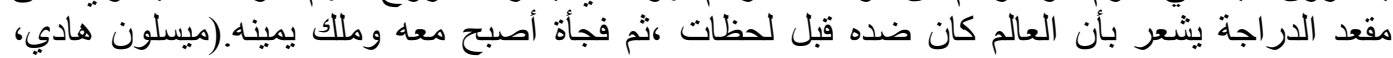

(76،2008

الر اوي هنا يرصد لنا شخصية مهنية أخرى وهي شخصية سفيان فنر اها شخصية مقاربة للشخصية محمد الشية

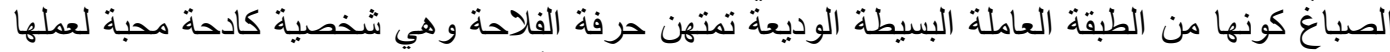

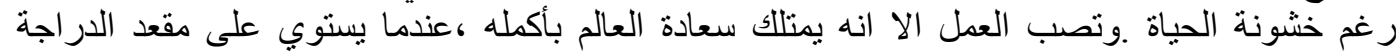

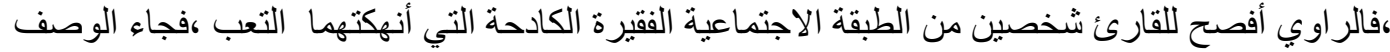




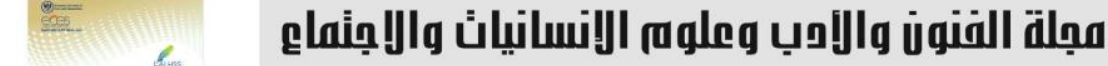 \\ Journal of Arts, Literature, Humanities and Social Sciences www.jalhss.com

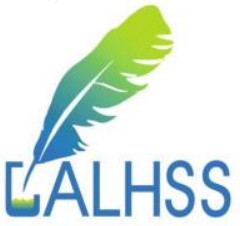

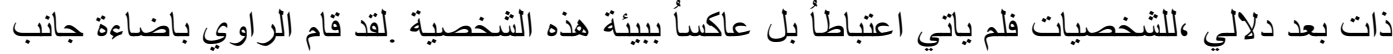

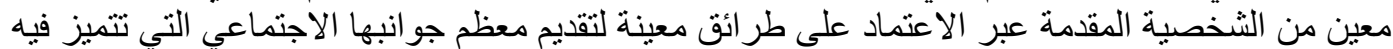

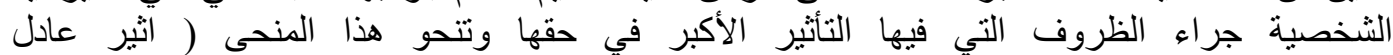

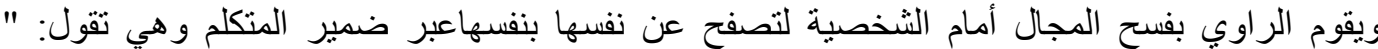

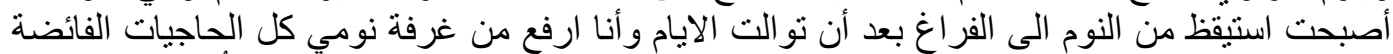

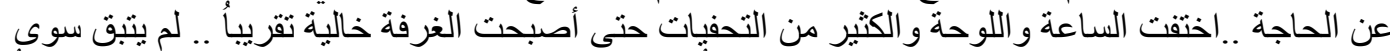

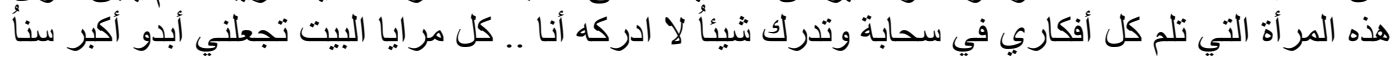

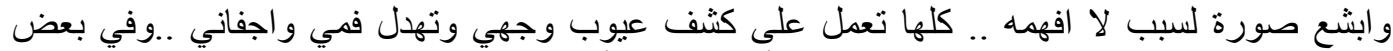

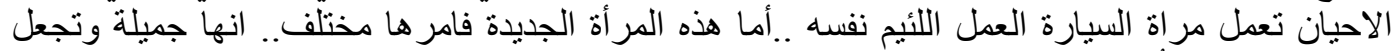

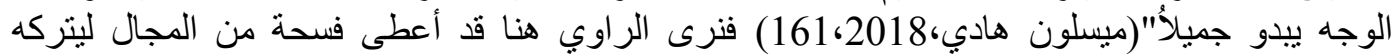

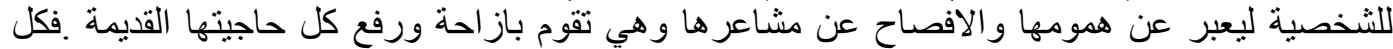

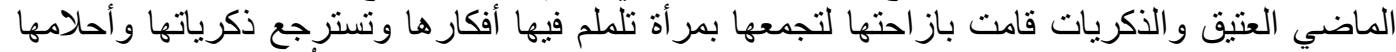

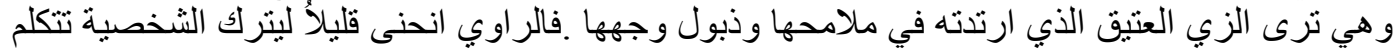

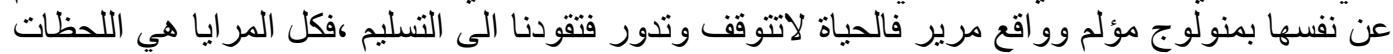

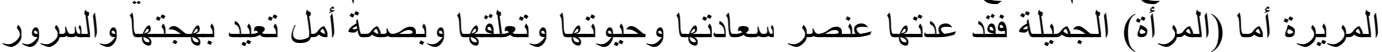

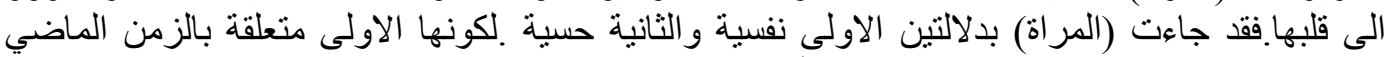

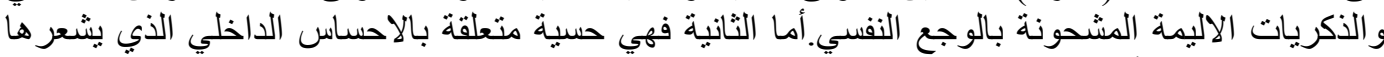

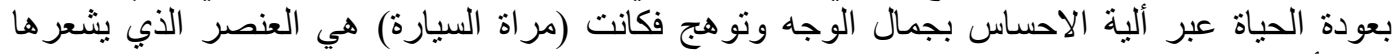
بالطمائنينة والثقة بالنفس والعة الاحدال المز اج.

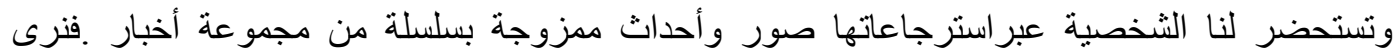

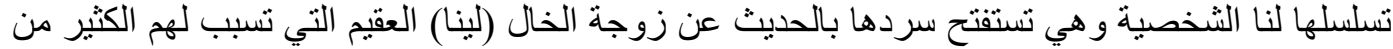
المشكلات بسبب نظر اتها الحاسدة.

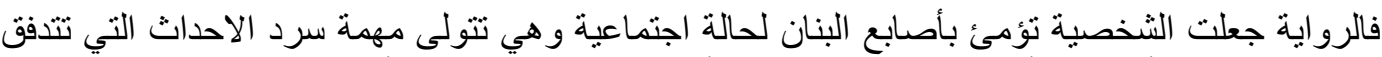

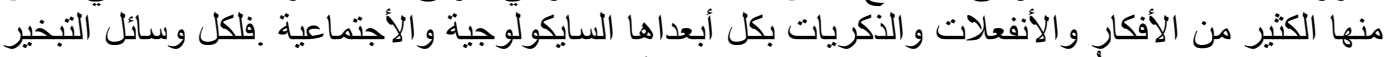

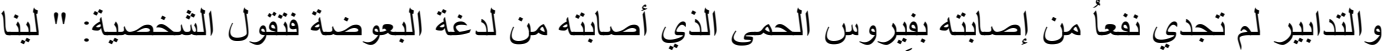

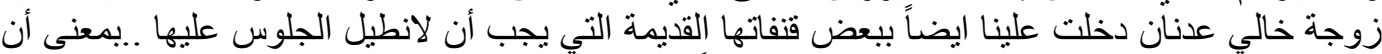

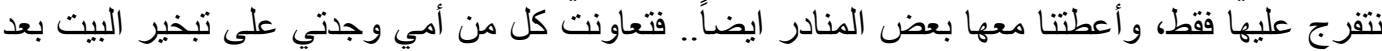

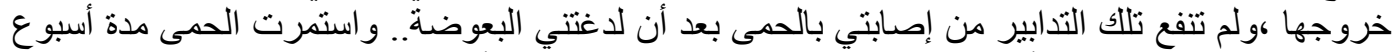

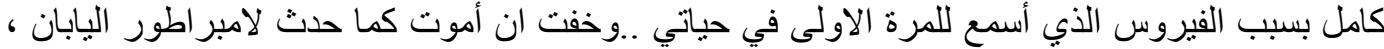

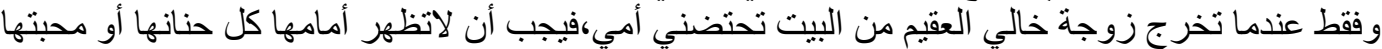

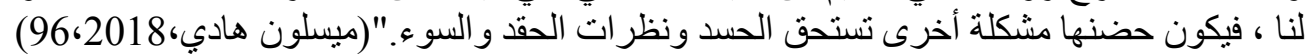

\section{المبحث الثالث}

\section{المكان (المبان}

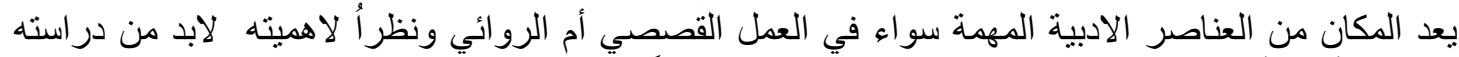

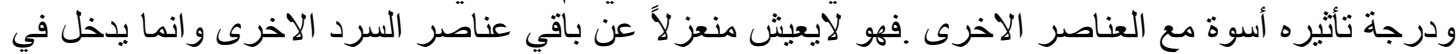

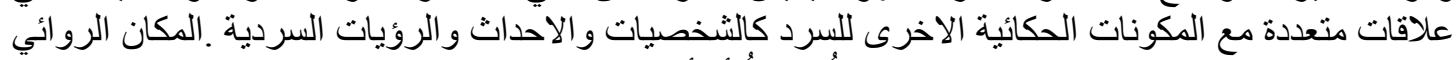

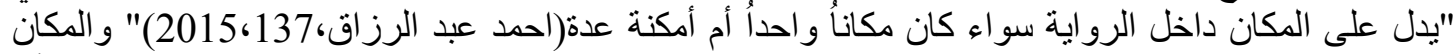
عند غالب هلسا هو" الصورة الفنية للعمل الادبي فهو وحدة العارف والتعرف التهان والمعروف،لان الفكر لايمكن أن الن النان 


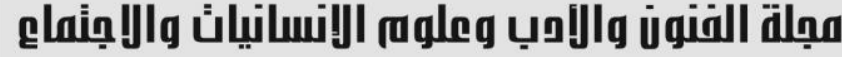

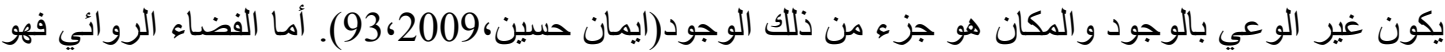

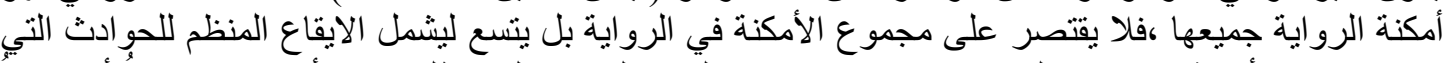

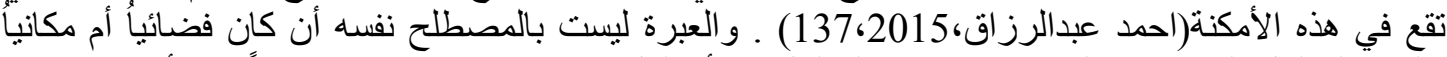

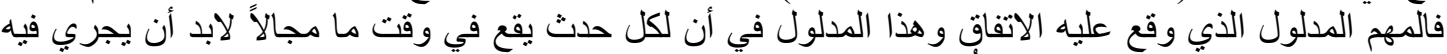

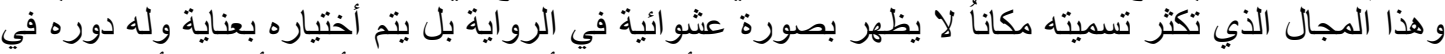

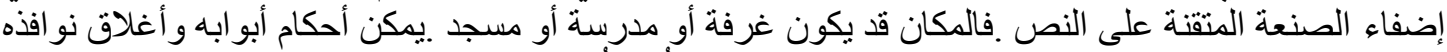

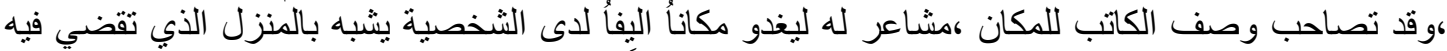

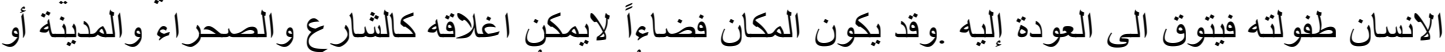

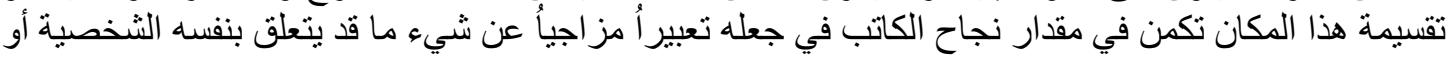

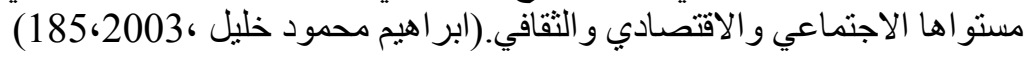

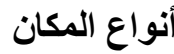

لقد ظهرت دراسات عديدة تهتم بدر اسة المكان و انو اعه ومن هذه الدر اسات هي در اسة غالب هلسا الذي قسم

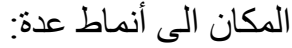

$$
\begin{aligned}
& \text { 1. المجازي : و هو المكان الذي تجري عليه أحداث الرواية . }
\end{aligned}
$$

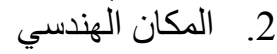

$$
\begin{aligned}
& \text { 3. المكان بوصفة تجربة معيشية العنية }
\end{aligned}
$$

أما شجاع العاني فقد ذهب الى تقسيم المكان الى 1. المكان المسرحي 2. المكان التاريخي 3. المكان الاليف 4.

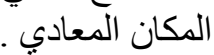

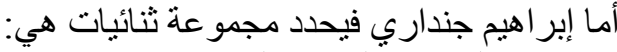

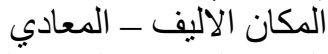

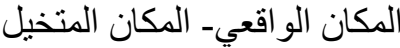

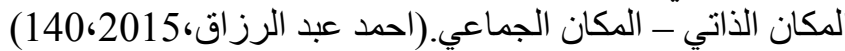

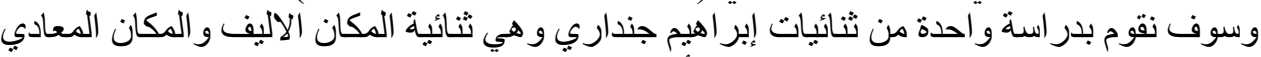

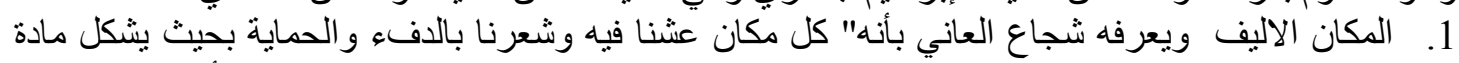

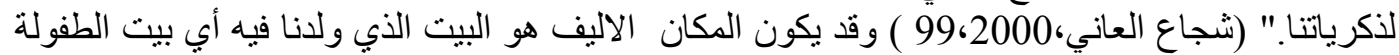

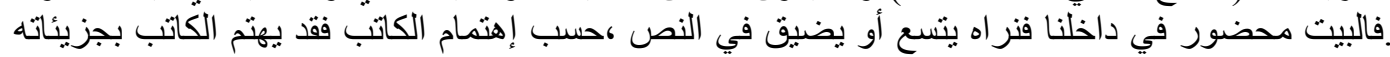

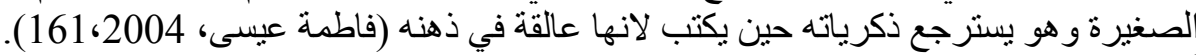

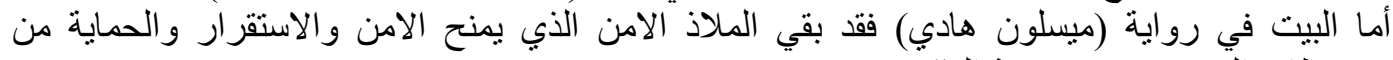

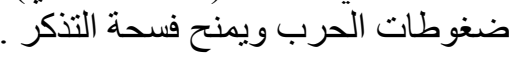

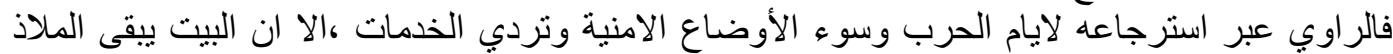

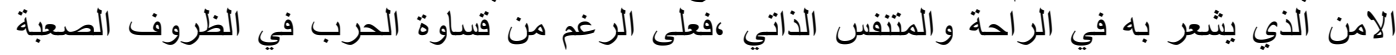

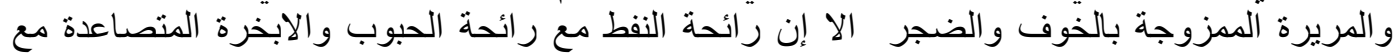

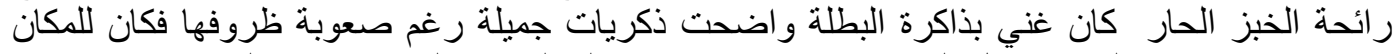

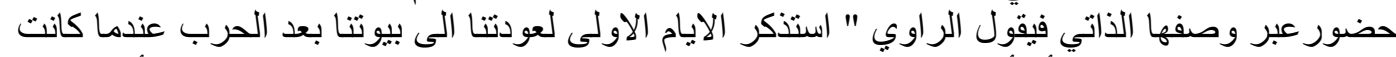

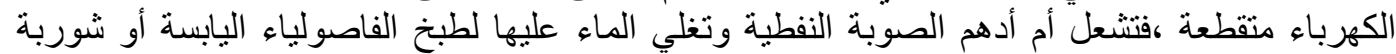

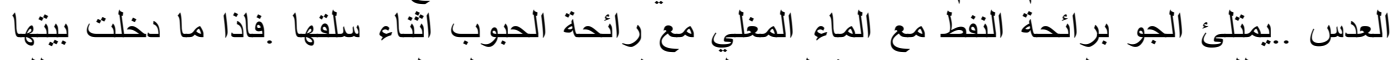

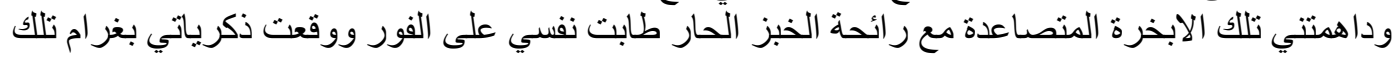

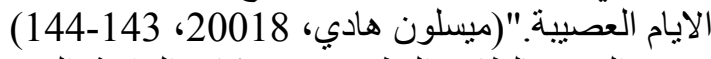

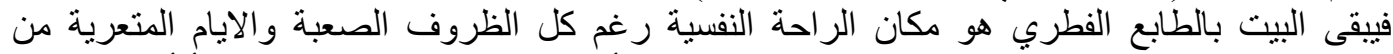

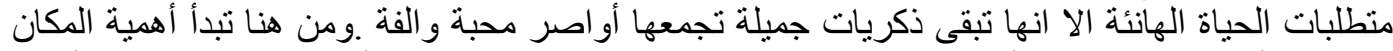
و علاقته بأحداث الرو اية وبالأخص علاقته بالانسان ،فلانسان و هو ينظر الى الأمكنة لايمنع نفسه من أخفاء 


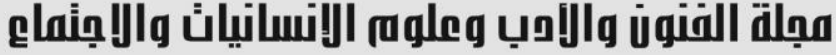

Journal of Arts, Literature, Humanities and Social Sciences www.jalhss.com

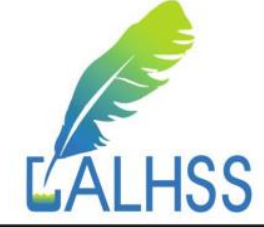

فكره ومزاجه و عو اطفه عليها وكل شيء في الرواية يوكد ذللك .وهكذا ومن خلال الكثف عن الكن خفايا هذه

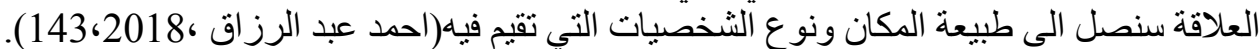

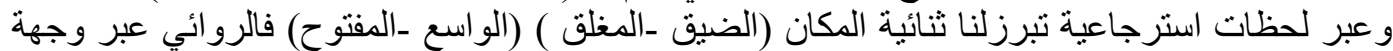

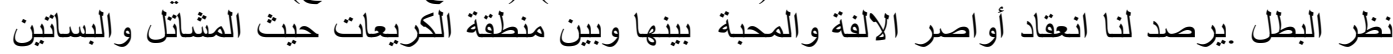

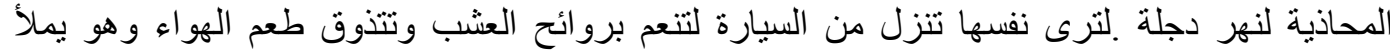

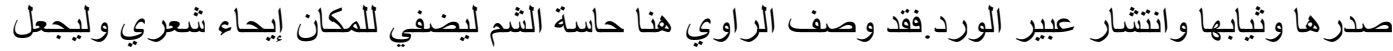

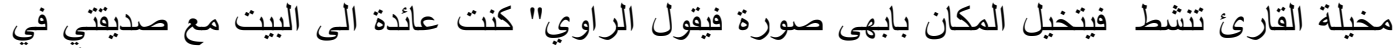

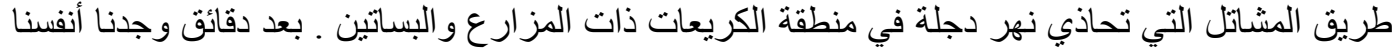

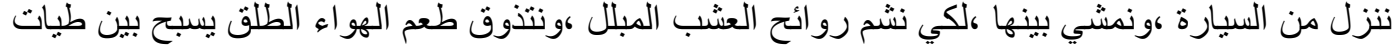

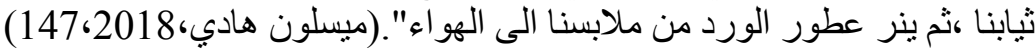

2. المكان المعادي: و هو " الاماكن التي نرغم المرء على العيش و الحياة فيها شاعر أ بالنفور و الكر اهية منها

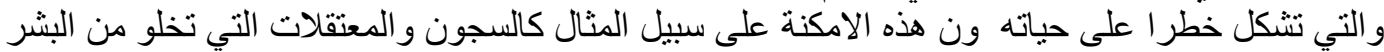

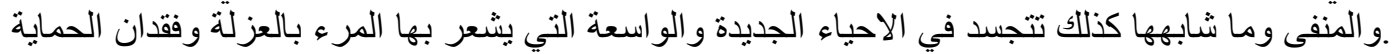

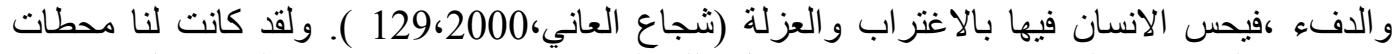

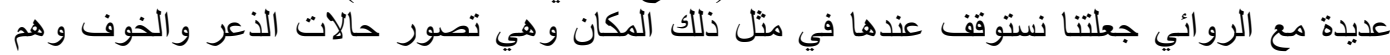

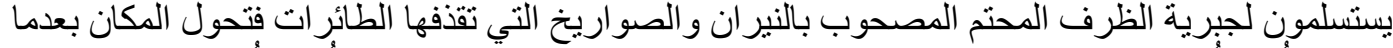

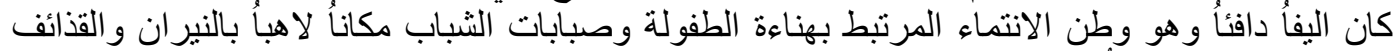

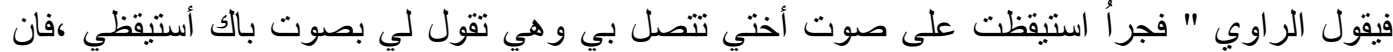

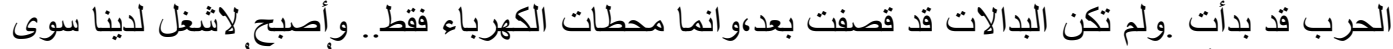

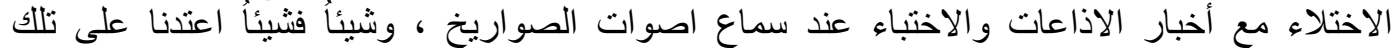

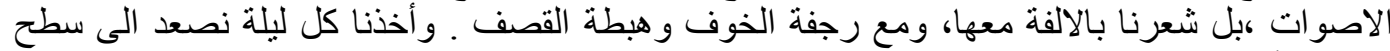

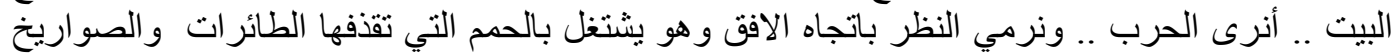

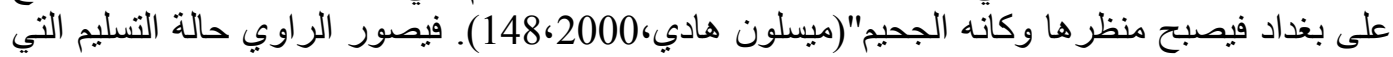

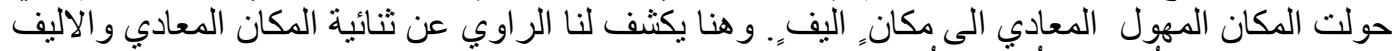

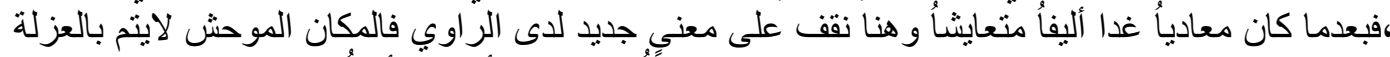

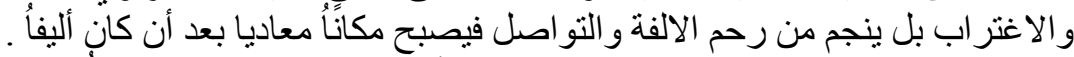

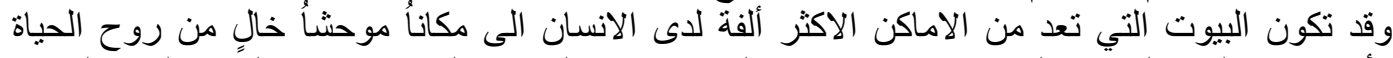

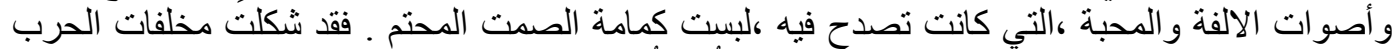

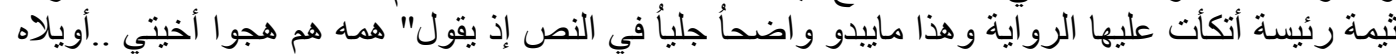

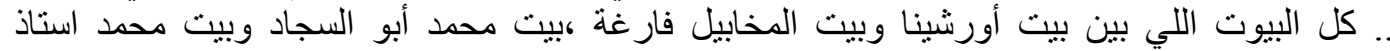

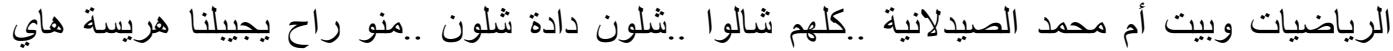

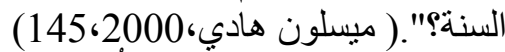

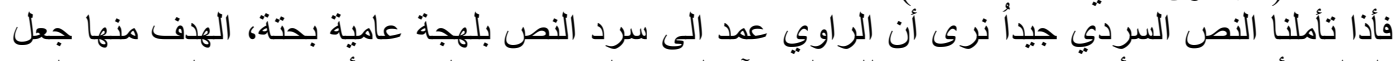

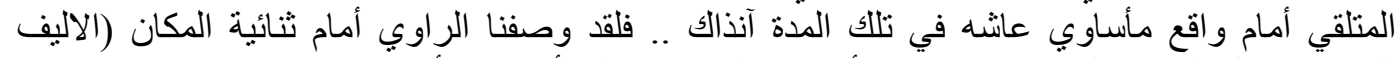

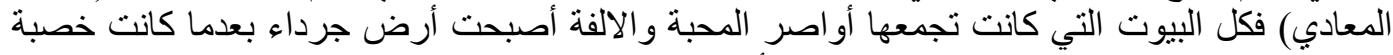

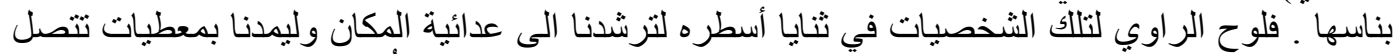

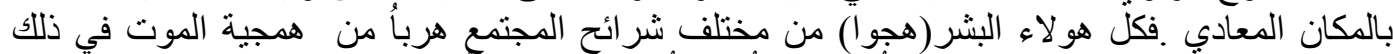

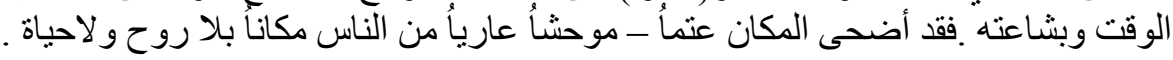




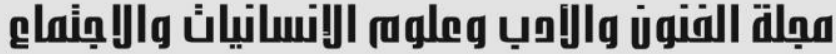

uellla aiall thes

Journal of Arts, Literature, Humanities and Social Sciences www.jalhss.com

1. تعد رواية (أخوة محمد) وثثقة تاريخة لجيل شهر ويلات الحرب وسيل الدماء و عانى من سرطان

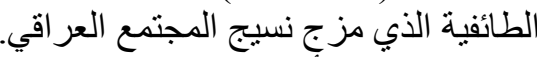

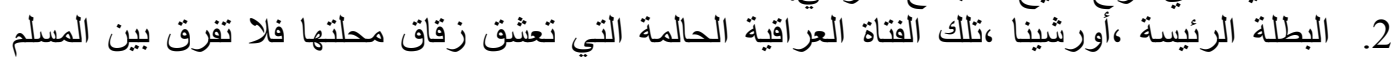

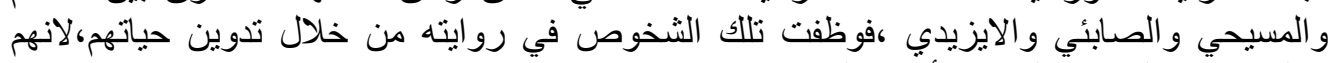

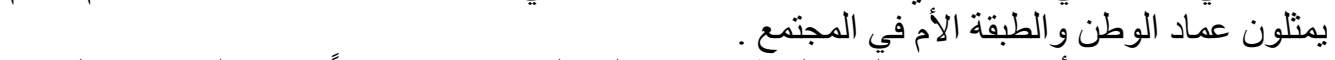

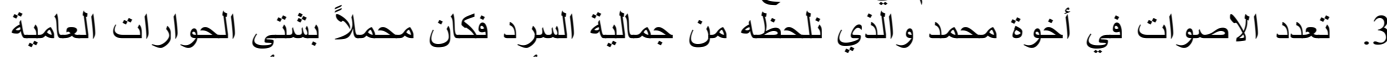

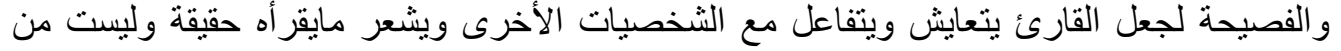

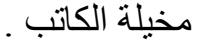
غلبة السرد الموضوعي على السرد الذاتي ،وهذا ما تبعه الكاتب في الرواية ،فكان حضور الذاتي

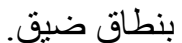
5. كان للمكان خصوصية لدى الكاتب و على وجه الخصوص المكان المعادي لانه برتبط ارتباطاُ نفسياً

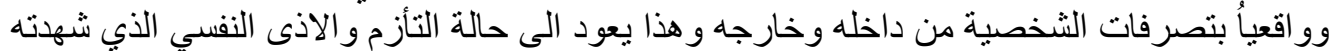
الشخصيات في ظروف الحرب. .5

1. احمد، زاوي. (2015). بنبة اللغة الحوارية في روايات محدد مفلاح. أطروحة دكتواره، كلية الاداب،

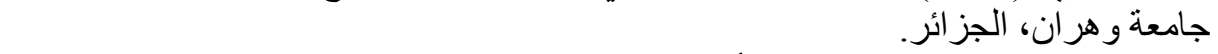

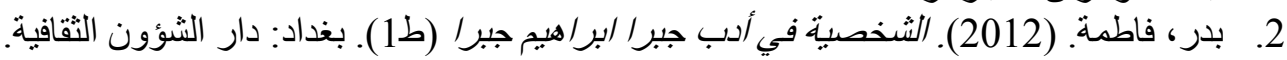

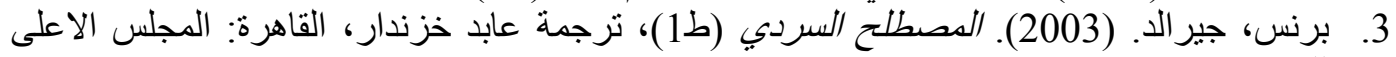

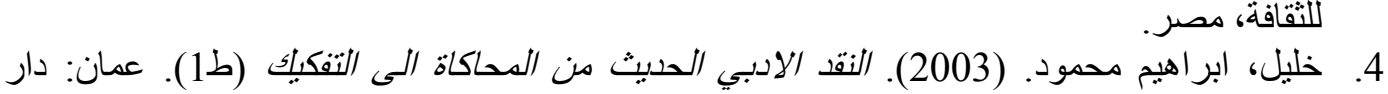

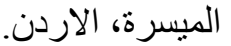

5. الثامي، حسن رشاد. (1998). المرأة في الرواية الفلسطبنية(1956-1985). منشورات اتحاد الكتاب

6. شواي، أثثر عادل. (2009). تقنيات تقليم الشخصية في الرواية العر/قية (ط1). بغداد: دار الثؤون الثقافية.

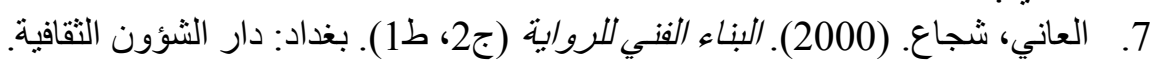

8.

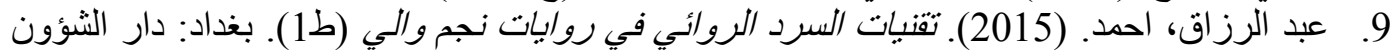

الثقافية.

10. عيسى، فاطمة. (2004). غائب طعدة فرمان روائباً (ط1). بغداد: دار الثؤون الثقافية. 11. محمد، بشرى ياسين. (2011). روايات حنان الثيخ دراسة في الخطاب الروائي (طانياني (1). بغداد: دار الشؤون الثقافية.

12. محيي، ايمان حسين. (2009). القصة القصبيرة بلفئة عند مبسلون هادي (دراسة فنبة وموضوعية). رسالة

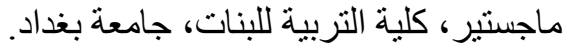
13. هادي، ميسلون. (2018). أخوة محدد (ط1). رواية. بغداد: دار الثؤون القافية. 


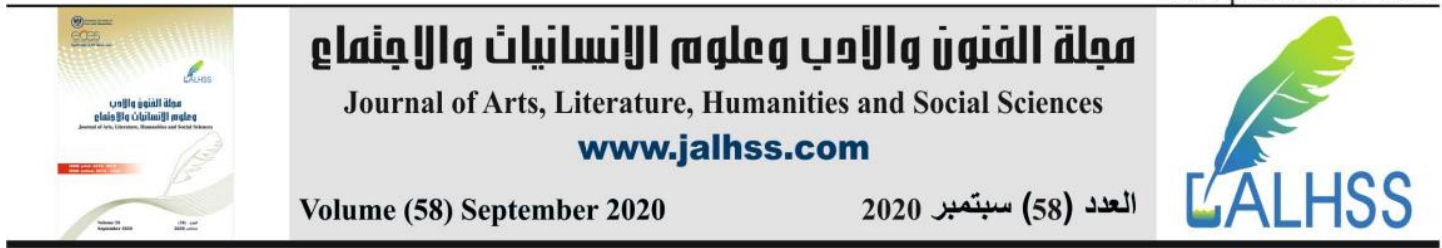

\section{References}

1. Ahmed, Zawy. (2015). The structure of the dialogic language in the novels of Muhammad Miflah. PhD thesis, Faculty of Arts, University of Oran, Algeria.

2. Badr, Fatima. (2012). The character in the literature of Jabra Ibrahim Jabra (1st ed.). Baghdad: House of Cultural Affairs.

3. Prince, Gerald. (2003). Narrative term (i-1), translated by Abed Khaznadar, Cairo: The Supreme Council of Culture, Egypt.

4. Khalil, Ibrahim Mahmoud. (2003). Modern literary criticism from simulation to deconstruction (i1). Amman: Maisarah House, Jordan.

5. Al-Shami, Hassan Rashad. (1998). The Women in the Palestinian Novel (19561985). Publications of the Arab Writers Union.

6. Shuai, just was raised. (2009). Techniques for presenting the character in the Iraqi novel (i 1). Baghdad: House of Cultural Affairs.

7. Ani, brave. (2000). The artistic construction of the novel (C2, i1). Baghdad: House of Cultural Affairs.

8. Ani, brave. (2012). The artistic construction of the novel, the building of perspective (C3, i1). Baghdad: House of Cultural Affairs.

9. Abdul Razzaq, Ahmed. (2015). Narrative narration techniques in the novels of Najm Wali (1st ed.). Baghdad: House of Cultural Affairs.

10. Isa, Fatima. (2004). Absent Tohma Farman, a novelist (ed. 1). Baghdad: House of Cultural Affairs.

11. Muhammad, Bushra Yassin. (2011). The novels of Hanan Al-Sheikh, a study in fictional discourse (i1). Baghdad: House of Cultural Affairs.

12. Mohi, Iman Hussein. (2009). The short story of Maysalun Hadi (technical and thematic study). Master Thesis, College of Education for Girls, University of Baghdad.

13. Hadi, Maysaloun. (2018). Brothers of Muhammad (i 1). a novel. Baghdad: House of Rhyme Affairs. 